\title{
On the Application of Contour Bumps for Transonic Drag Reduction (Invited)
}

\author{
William E. Milholen II ${ }^{*}$ and Lewis R. Owens. ${ }^{\dagger}$ \\ NASA Langley Research Center, Hampton, VA, 23681-2199
}

\begin{abstract}
The effect of discrete contour bumps on reducing the transonic drag at off-design conditions on an airfoil have been examined. The research focused on fully-turbulent flow conditions, at a realistic flight chord Reynolds number of $\mathbf{3 0}$ million. State-of-the-art computational fluid dynamics methods were used to design a new baseline airfoil, and a family of fixed contour bumps. The new configurations were experimentally evaluated in the $0.3-\mathrm{m}$ Transonic Cryogenic Tunnel at the NASA Langley Research center, which utilizes an adaptive wall test section to minimize wall interference. The computational study showed that transonic drag reduction, on the order of $12 \%-15 \%$, was possible using a surface contour bump to spread a normal shock wave. The computational study also indicated that the divergence drag Mach number was increased for the contour bump applications. Preliminary analysis of the experimental data showed a similar contour bump effect, but this data needed to be further analyzed for residual wall interference corrections.
\end{abstract}

\section{Nomenclature}

$\mathrm{c} \quad=$ airfoil chord

$\mathrm{C}_{\mathrm{d}} \quad=$ airfoil drag coefficient

$\mathrm{C}_{1} \quad=$ airfoil lift coefficient

$\mathrm{C}_{\mathrm{m}} \quad=$ airfoil pitching moment, about $0.25 \mathrm{c}$

$\mathrm{C}_{\mathrm{p}} \quad=$ surface pressure coefficient

$\mathrm{C}_{\mathrm{p}}{ }^{*}=$ sonic value of surface pressure coefficient

$\mathrm{h} \quad=$ maximum crest height of contour bump

$\mathrm{M}=$ local value of Mach number

$\mathrm{M}_{\mathrm{DD}}=$ drag divergent value of freestream Mach number

$\mathrm{M}_{\infty} \quad=$ freestream Mach number

$\mathrm{Re} \quad=$ Reynolds number based on chord

$\mathrm{x}, \mathrm{Z}=$ two dimensional Cartesian coordinate system

$\alpha \quad=$ angle-of-attack, degrees

\section{Introduction}

$\mathrm{T}$ he area of transonic drag reduction has been a long-standing topic of research, which has been fueled largely by the commercial transport industry. Aerodynamic prediction codes and testing techniques have been developed which allow designers to develop aircraft, which perform efficiently at design conditions. Methods to improve the off-design performance of commercial transports are always being examined, as the off-design characteristics often play a strong role in the sizing and/or range of a given configuration. One method, which has been proposed to improve the off-design performance of a transonic aircraft, is a wing that can change shape, or "morph" to mitigate adverse off-design effects. A frequent goal of improving off-design performance focuses on reducing drag, particularly the wave drag generated by shock waves on the aircraft. Thus, a wing that could locally change shape to decrease the shock wave strength would be highly advantageous. One such method that has been proposed is shown in Fig. 1 on an airfoil, which depicts a discrete contour bump deployed at the normal shock wave location, spreading and weakening the shock wave. On an aircraft, the contour bumps would be part of an active system, whereby they would be deployed in an intelligent fashion to minimize drag. Thus an aircraft designed to take advantage of such an active drag reduction system would have an increased range and reduced operating costs, assuming any potential weight penalties can be overcome.

\footnotetext{
${ }^{*}$ Research Engineer, Configuration Aerodynamics Branch, MS 499, Senior Member AIAA.

${ }^{\dagger}$ Research Engineer, Flow Physics and Control Branch, MS 170, Senior Member AIAA.
}

This material is declared a work of the U.S. Government and is not subject to copyright protection in the United States. 


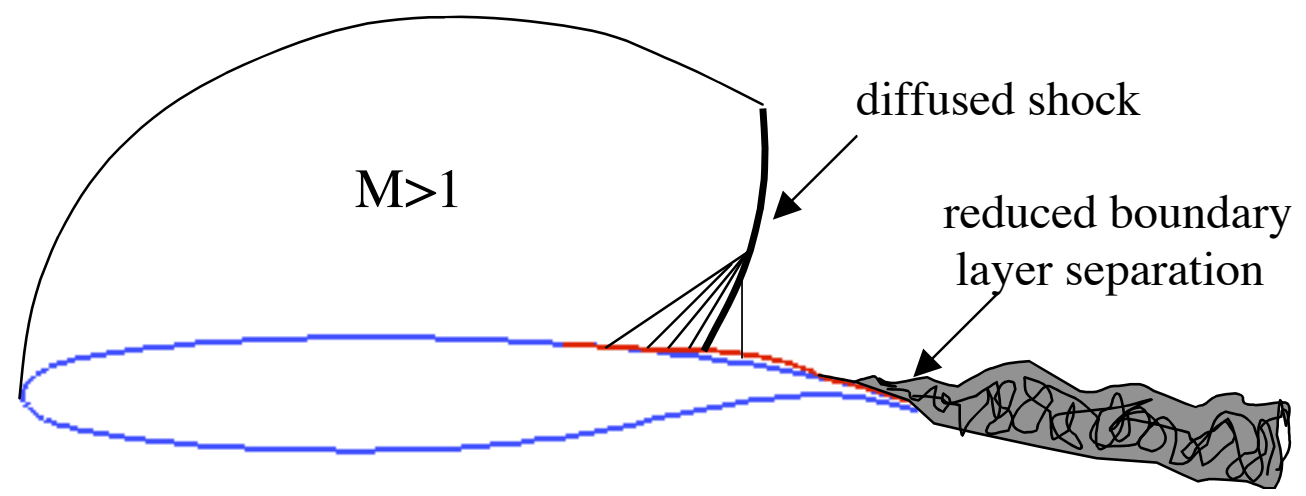

Figure 1: Contour bump deployed near normal shock wave on airfoil upper surface.

Research that supports the use of surface contour bumps has theoretical beginnings in the late 1970's. Early developments in supercritical airfoil technology provided for a weak normal shock wave at the airfoil design Mach number and lift coefficient. However, moving away from this design condition, problems of both drag divergence and buffeting became significant. Studies to investigate methods to improve off-design performance for these types of transonic airfoils became a focus. One such study examined the theoretical aspects of designing a "dromedaryfoil" (Ref. 1). The goal of this study was to theoretically design a hump to isentropically pre-compress the flow ahead of the upper surface normal shock wave to reduce the pre-shock velocity so that the wave drag was minimized and then rapidly recompress the subsonic flow aft of the shock while maintaining high lift levels. This theoretical work was followed in the 1980's by some experimental investigations to carefully check the performance of some of these humped airfoil designs at transonic conditions (Ref. 2). The results indicated that some aspects of the humped airfoil improved the off-design supercritical performance, but there was room for further improvements. The principal researcher concluded that these further improvements are to be realized through the application of "new, sophisticated computational fluid dynamics." Also, it should be noted that these humped airfoils were generally viewed as a static system that were not capable of changing the hump shape or location during operation.

In Europe in the early 1990's, a systematic and thorough research effort was implemented to help develop enabling technologies for gaining a larger share of the aviation industry's global market. The first phase of this research program was called Euroshock I, which focused on drag reduction through passive shock control (Refs. 3, 4). This work approached the drag reduction problem using laminar airfoil technology and tried to use venting and boundary layer suction close to the upper surface shock to reduce wave drag. Results generally suggested that it was possible to achieve wave drag reduction through passive control, but the overall drag was not reduced because of the increased viscous drag associated with the surface porosity under the shock wave. A significant finding from this research was that the vented cavity beneath the shock produced a secondary flow field that created a ramping effect under the shock. This ramping effect contributed to the wave drag reduction by spreading the normal shock into a weaker series of oblique shock waves. With this understanding, the Europeans launched a second phase of this research in the late 1990's to develop surface contour bump technology to leverage this wave drag reduction mechanism (Refs. 5-10). It should be noted that the focus on laminar airfoil technology was maintained. The results of this extensive study demonstrated that it was possible to reduce the total drag of a wing by utilizing contour bump technology to reduce wave drag.

In 2001, NASA's Aircraft Morphing project began a closer examination of the possibility of using surface contour bumps to reduce aircraft wing drag (Ref. 11). The approach of this study considered two application goals, a short term one and a long term one, both shown in Fig. 2. The short-term goal is focused on the design and development of a surface contour bump limited to $20 \%$ of the airfoil chord. This application would be suited for application to current transport aircraft wings, which typically have spoiler surfaces of this extent that may be modified to include a shock-control contour bump. This approach is the same proposed by the extensive body of research conducted in the Euroshock II program. The long-term goal is focused on the design and development of a surface contour bump that would cover as much as the last $40 \%$ of the airfoil chord. This application is new and requires an integration of this and other technologies from the beginning of the aircraft wing design process. For example, since the bump covers the last $40 \%$ of the airfoil chord, a typical control flap would not be used. The 


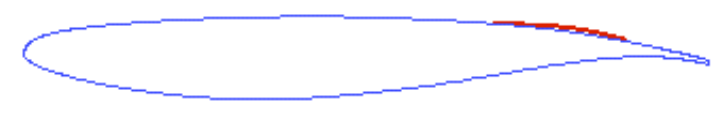

Near Term Goal

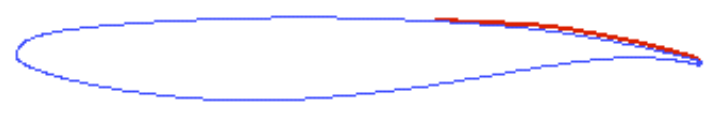

Long Term Goal

Figure 2: Near-term and long-term goals for contour bumps.

longer bump itself would provide for the possibility of camber changes, plus possible integration of wing circulation control technology, which could be used to achieve the lift control usually provided by a trailing-edge control flap.

Surface contour bumps can be applied to commercial transport aircraft to reduce drag at off-design conditions in several ways. Two primary applications include reducing drag penalties incurred by either operating an aircraft at increased speed, or flying at cruise speed with a non-optimal lift coefficient. The drag reduction potential for both situations can be quiet similar. In the present study, the off-design scenario considered is that of a speed increase, while maintaining a constant lift coefficient. The objective of the current research examines the size and shaping of small contour bumps on a cruise wing upper surface, as a means by which to spread the shock wave, and thereby reduce transonic drag for this off-design condition. Computational fluid dynamics codes and design methods are used to design several contour bumps for a new state-of-the-art, fully-turbulent transonic airfoil, which operates at realistic flight Reynolds numbers. The contour bump designs have recently been experimentally evaluated in a high-Reynolds number wind tunnel at the NASA Langley Research Center. This paper will give a general overview of the aerodynamics research project, and will not discuss the ongoing structural design research for application to aircraft.

\section{Computational Methods}

The flow solvers utilized for the research were the Euler/integral boundary layer code MSES, and the unstructured Navier-Stokes solver FUN2D. The MSES code was chosen for its speed and accuracy in computing flow fields with fully attached flows, or small regions of separation (Ref. 12). The speed of the code was advantageous in determining configurations for further study with FUN2D, while the optimizer available with MSES was found to be a useful design tool. In addition, both flow solvers have been coupled for use with the CDISC design method (Ref. 13) developed at the NASA Langley Research Center. Since the research focuses on realistic flight Reynolds numbers, the simulated flow fields were assumed to be fully turbulent. It should also be noted that all airfoil computations discussed below use appropriate boundary conditions to simulate free-air flow fields, and do not include the effects of wind tunnel walls. The salient features of each flow solver will be briefly discussed below.

\section{A. MSES}

The MSES code solves the time dependent Euler equations in a streamline fitted coordinate system, using a finite volume discretization. To simulate viscous flows, a two-equation integral boundary layer method is used. The streamline at the surface of the airfoil is offset a distance equal to the local boundary layer displacement thickness. The resulting coupled flow field analysis is then solved using a full-Newton iteration scheme, and is converged to a steady state solution. The available design and optimization code, LINDOP, was utilized to design the new baseline 2-D airfoil, as well as one of the contour bumps, which will be discussed below. Complete details of the method are found in Ref. 14.

\section{B. FUN2D}

The FUN2D code solves the time dependent 2-D Reynolds-averaged Navier-Stokes equations using unstructured grids. A node-based finite volume formulation is used to discretize the governing equations, with the solution being advanced to steady state using an implicit upwind differencing scheme based on the flux-difference splitting technique of Roe. The effects of turbulence are simulated using the one-equation Spalart-Allmaras turbulence model. Ref. 15 provides an in depth discussion of the flow solver. 
An automated script was used to monitor convergence and to efficiently drive the solutions to prescribed lift coefficients if desired. The solutions were considered converged when the root-mean-square value of the lift coefficient varied less than $0.01 \%$ over the last 100 iterations. This typically required 4000 flow solver iterations, and resulted in a five-order decrease in the residual of the continuity equation. Grid refinement studies were conducted, but the results will not be presented for the sake of brevity (Ref. 16). The results presented however, are considered to be grid independent. Figure 3 shows a partial view of a typical unstructured grid used, generated using the AFSOR code (Ref. 17). The airfoil surface is represented by 600 surface nodes, resulting in a grid with approximately 50,000 nodes. The viscous spacing at the airfoil surface was chosen to give a $y^{+}$value for the $1^{\text {st }}$ cell away from the surface in the range of 0.5-1.0.

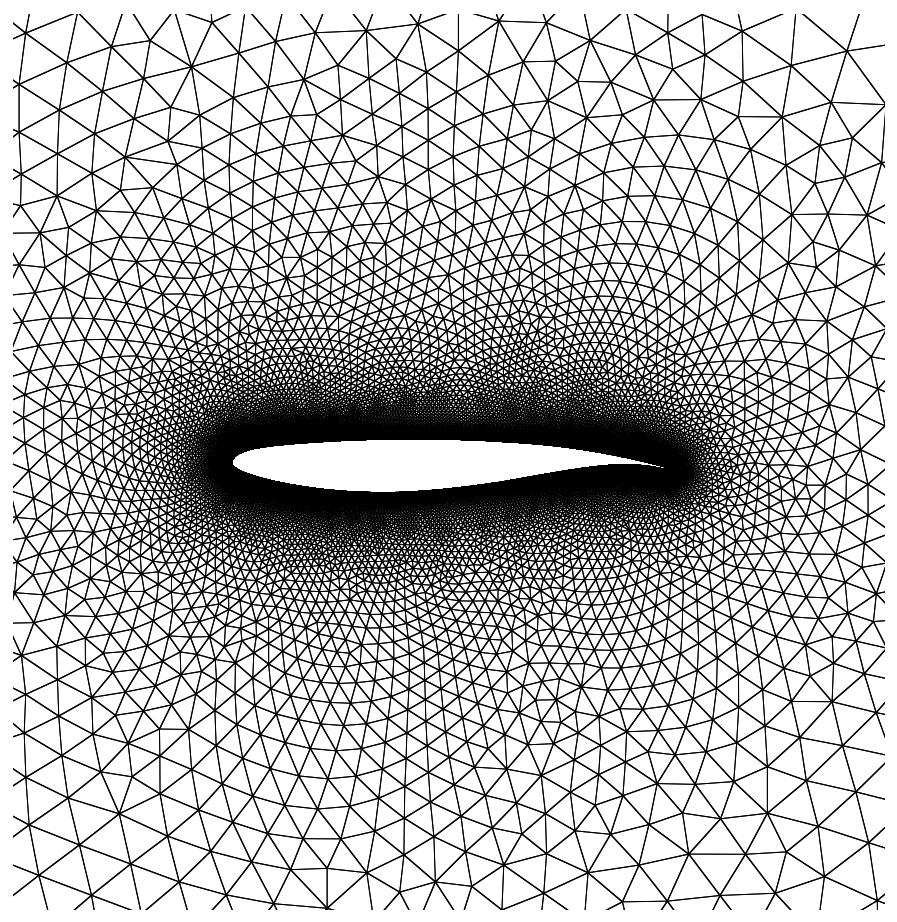

Figure 3: Partial view of unstructured grid for TMA-0712 airfoil.

\section{Baseline Airfoil Design}

A new state-of-the-art transonic airfoil was designed specifically for the contour bump research. The new airfoil's designation is: NASA TMA-0712. The TMA acronym stands for TransonicMorphing Airfoil, while the 0712 signifies a design lift coefficient of 0.70 and a maximum thickness to chord ratio of $12 \%$. The design Mach number for the airfoil is 0.76 at a flight chord Reynolds number of $30 \times 10^{6}$. A multi-point design optimization was conducted using MSES and the LINDOP optimizer. The objective of the airfoil design was to minimize the drag coefficient while maintaining the lift coefficient at the design Mach number of 0.76, and at an off-design Mach number of 0.78 . For the design, the flow was assumed to be fully turbulent. The seed airfoil for the design was the NASA SC(3)-0712 airfoil (Ref. 18). The drag divergence characteristics of the new airfoil at the design lift coefficient are shown in Fig. 4. The FUN2D and MSES results are found to agree quiet well up to the off-design Mach number. Using the FUN2D prediction, the drag divergence Mach number is 0.775, based on an increase of 20 drag counts above the value at $\mathrm{M}_{\infty}=0.70$. 


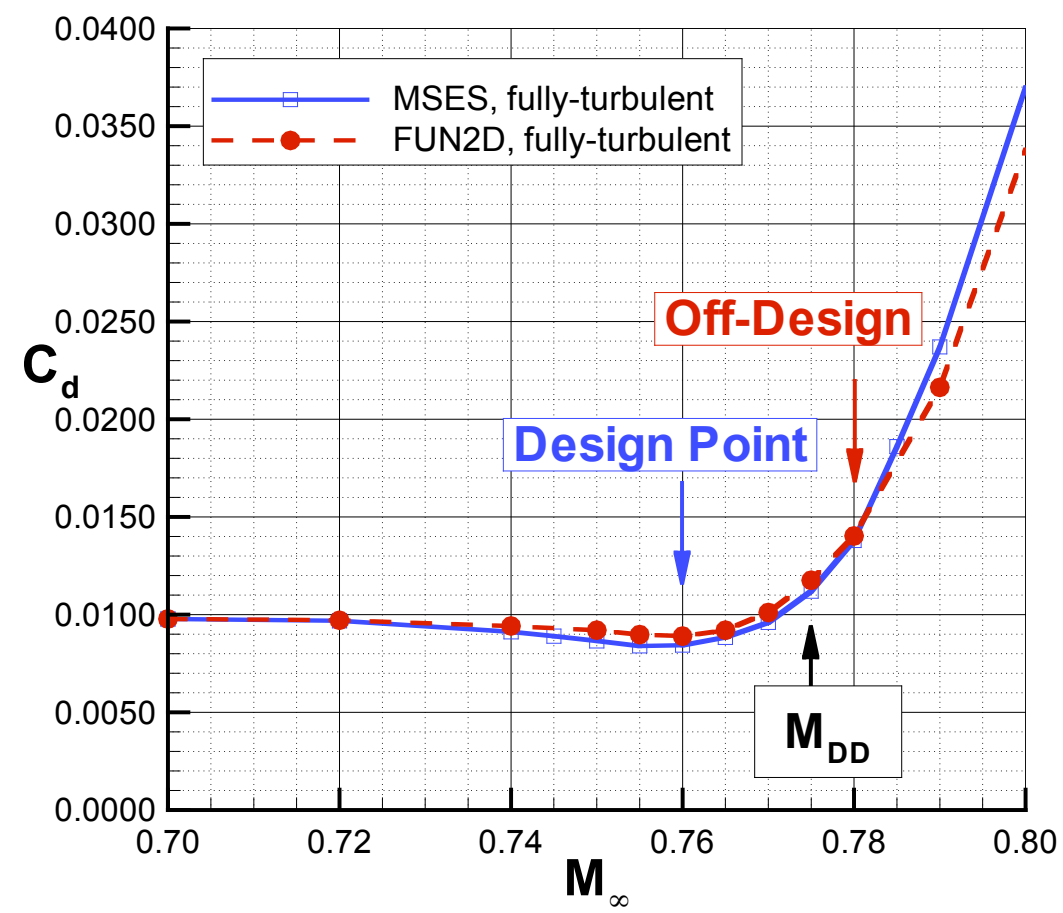

Figure 4: Drag divergence characteristics of the NASA TMA-0712 airfoil $\left(C_{1}=0.70, \operatorname{Re}=30 \times 10^{6}\right)$.

\section{Contour Bump Design}

A family of static contour bumps has been designed for the new airfoil at the off-design Mach number of 0.78 . As discussed above, near-term and long-term morphing goals have been developed, which encompass two different chord lengths for the contour bump. Two contour bumps were designed for the near-term goal with lengths equal to $20 \% \mathrm{c}$. The first contour bump, Bump1, was designed using the CDISC design method coupled with MSES. A target surface Mach number distribution was formulated to simulate a lambda-shaped shock wave structure. A second contour bump was designed using the LINDOP optimizer in conjunction with MSES, and was referred to as Bump2. The drag reduction characteristics were nearly identical to those of Bump1, and it was not pursued further. Another contour bump, Bump3, was designed for the long-term goal again using LINDOP with MSES. The two remaining contour bumps, were analyzed extensively with both MSES and FUN2D.

\section{Wind Tunnel Testing}

The wind tunnel experiment was performed on the TMA-0712 airfoil model with a 6-inch chord using NASA Langley's 0.3-m Transonic Cryogenic Tunnel (TCT). The airfoil model was designed to have a common leadingedge section up to $50 \% \mathrm{c}$, with the remaining half of the chord made up of one of six different trailing-edge sections. These trailing-edge sections included one for the Baseline (no contour bump) configuration, four height variations of the Bump1 configuration, and one for the Bump3 configuration. The airfoil model was instrumented with chordwise and upper surface span-wise pressure orifices. The chord-wise pressure orifices were integrated to provide a calculation of the normal force and pitching moment coefficients, while the span-wise pressure orifices were used to document the extent of 2-D flow above the airfoil model during testing. The model passed through two windows and connected to mounting brackets in the tunnel plenum area. A photograph of the airfoil model installed in the tunnel test section is shown in Fig. 5. The tunnel sidewall turntables provided an angle-of-attack ranging from $-3^{\circ}$ to $+3^{\circ}$. The windows provided visual access for a focusing Schlieren system to capture digital images of the shock wave patterns above the airfoil upper surface. The airfoil drag was calculated by integrating a wake rake survey that was located three chord lengths downstream of the airfoil trailing edge. 


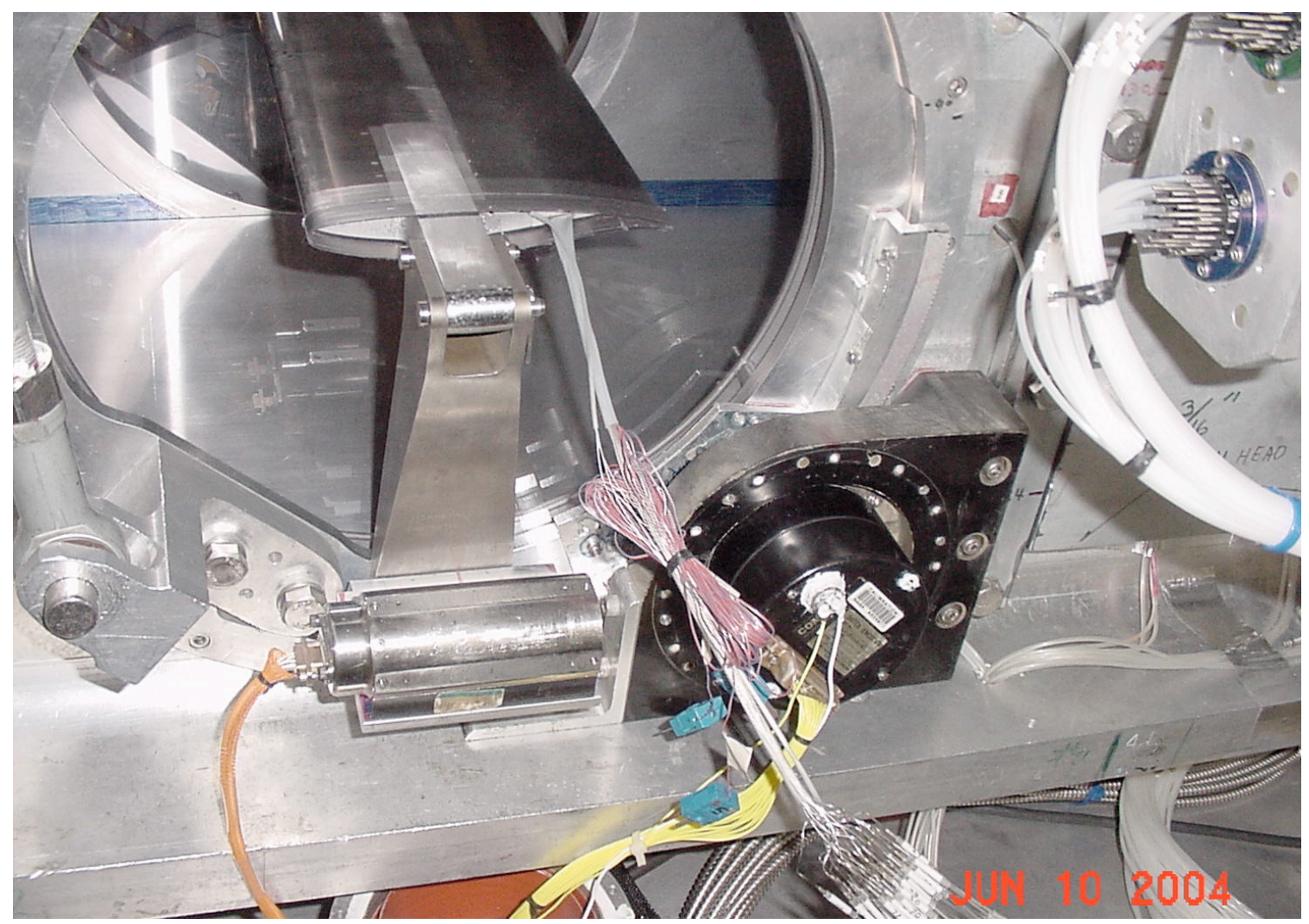

Figure 5: Photograph of the TMA-0712 airfoil model (6-inch chord) in the 0.3-m TCT test section.

The 0.3-m TCT is described in Ref. 19 as a fan-driven, cryogenic, adaptive-wall pressure tunnel that uses gaseous nitrogen as a test gas. The facility operates within a temperature range from $327 \mathrm{~K}\left(130^{\circ} \mathrm{F}\right)$ to approximately $80 \mathrm{~K}\left(-316^{\circ} \mathrm{F}\right)$ and a pressure range from 1.2 to 6.0 atmospheres $(17.6$ to 88.0 psia). The test section cross-section is nominally 13.0 -in. x 13.0-in., and has a length of 72.0 inches. The flexible floor and ceiling are streamlined during testing to minimize wall interference effects on the data. Post-test corrections are generally required to correct the data for residual wall interference effects, and account for the presence of the sidewall boundary layers on the model (Ref. 20).

\section{Results}

All data presented and discussed below are at a constant chord Reynolds number of 30x10 ${ }^{6}$, representative of typical flight conditions for a commercial transport aircraft. A representative subset of the FUN2D predictions will be presented first, followed by a discussion of preliminary data from the recent high-Reynolds number wind tunnel experiment.

\section{A. FUN2D Predictions}

The effect of the contour bump height for both shapes is presented in Fig. 6 for the off-design condition. The percent change in the drag coefficient relative to the baseline TMA-0712 airfoil is plotted versus the nondimensional maximum contour bump height. The design point for each bump family is shown. The contour bumps are clearly capable of generating significant drag reduction, in the range of $12 \%-15 \%$. The CDISC designed contour bump, Bump1, does benefit from a slight increase in crest height. The third bump, designed using LINDOP, was much closer to the optimal height. Both shapes demonstrate a desirable plateau in drag reduction near their respective optimal crest heights. For comparison, the isolated contour bumps are also shown with an expanded vertical scale. Although not obvious in the results presented here, the crest of the contour bumps was located approximately $1.0 \%-2.0 \%$ chord downstream of the normal shock wave location. 


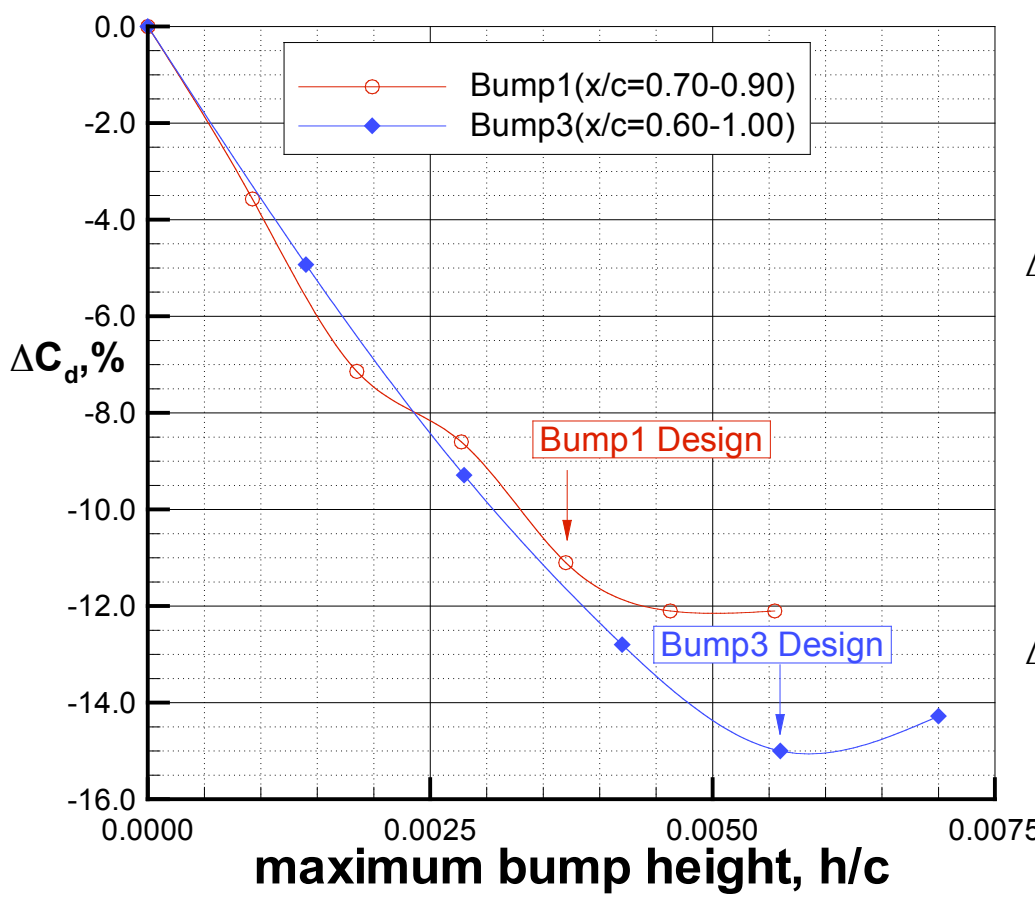

Bump1(0.0018 $\mathrm{h} / \mathrm{c} \leq 0.0046)$
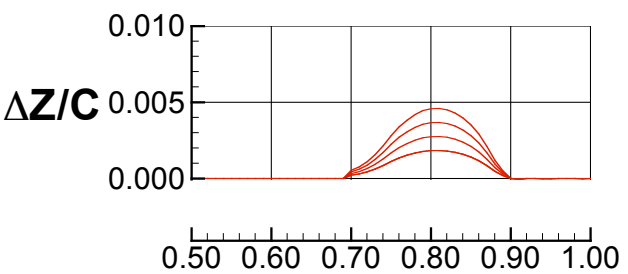

Bump3(0.0014 $\leq \mathrm{h} / \mathrm{c} \leq 0.0056)$
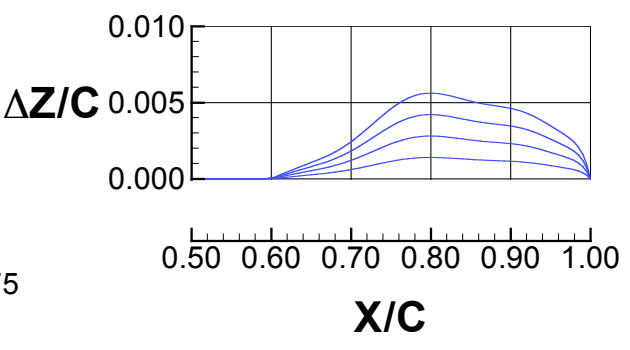

Figure 6: Effect of contour bump height on predicted drag reduction for the NASA TMA-0712 airfoil $\left(M_{\infty}=0.78, C_{1}=0.70, \operatorname{Re}=30 \times 10^{6}\right)$.

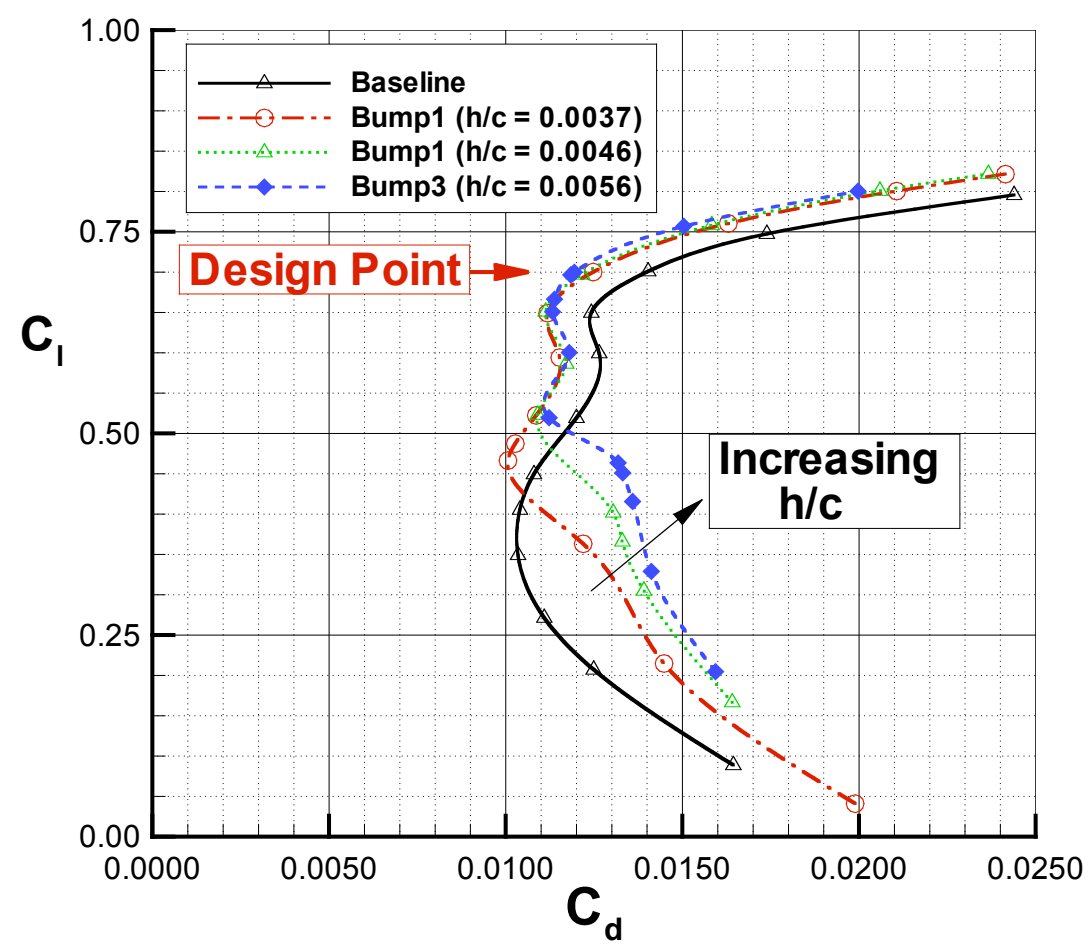

Figure 7: Effect of contour bump on predicted drag polar for the NASA TMA-0712 airfoil

Figure 7 demonstrates the effect of several contour bumps on the drag polar, with the design point of $\mathrm{C}_{1}=0.70$ noted. Several important observations can be drawn from the comparison. The static bump shapes show significant drag reduction over a wide range of lift coefficients, not just at the design point. At the highest lift coefficient of 0.80 , the predicted drag reduction is $22 \%$ for Bump3. As the lift coefficient decreases below 0.50 , the fixed bump shapes create a substantial drag penalty. This occurs because the shock wave on the airfoil upper surface moves forward of the contour bump. The flow re-accelerates over the bump, and a second normal shock wave forms aft of the contour bump. In addition, the resulting double shock wave pattern separates the boundary layer, further 

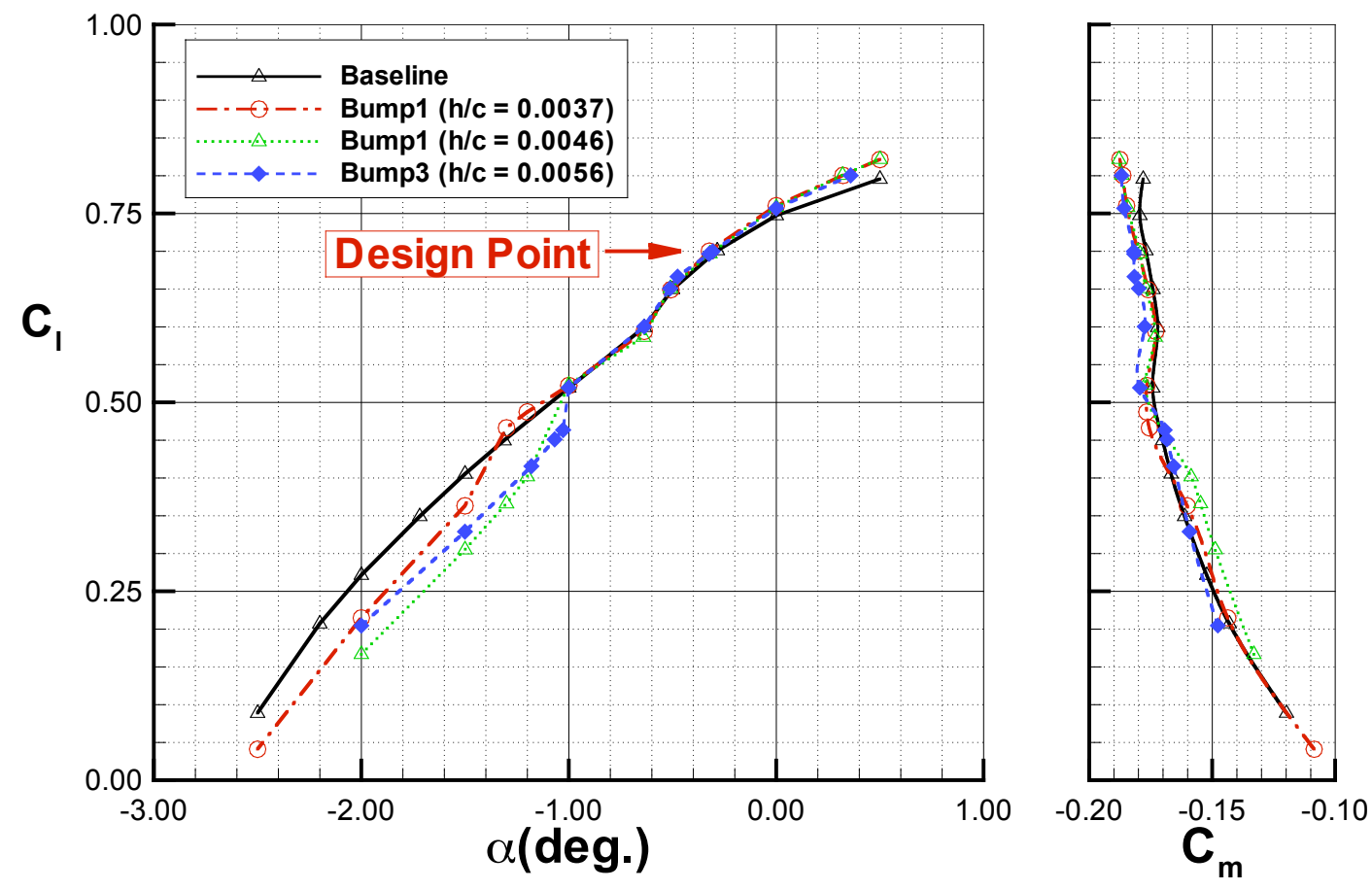

Figure 8: Effect of contour bump on predicted lift and pitching moment coefficients for the NASA TMA-0712 airfoil $\left(M_{m}=0.78, R e=30 \times 10^{6}\right)$.

increasing the drag coefficient. As expected, decreasing the contour bump height reduces the drag penalty. These results demonstrate that an active contour bump, which could change height and translate to follow the shock wave, would further enhance the performance of the contour bump, and insure no drag penalties over the baseline configuration.

The impact of the contour bumps on the lift and pitching moment coefficients are illustrated in Fig. 8 . The degradation in the contour bump configurations below $-1.0^{\circ}$ angle-of-attack is clearly seen, being attributed to the double shock wave system on the upper surface. For lift coefficients above 0.50, the contour bumps are not detrimental to lift, and even enhance lift at the highest angles-of-attack. The pitching moment does become slightly more negative in this lift regime, with the increment increasing with bump height. It is anticipated that the application of the active contour bump concept to a complete aircraft configuration would not introduce pitch control problems, but a pitch trim drag assessment is needed to fully characterize potential benefits.

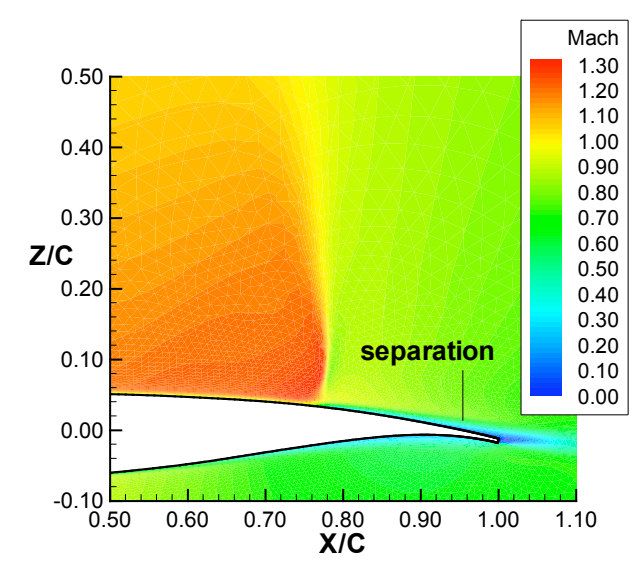

a)Baseline

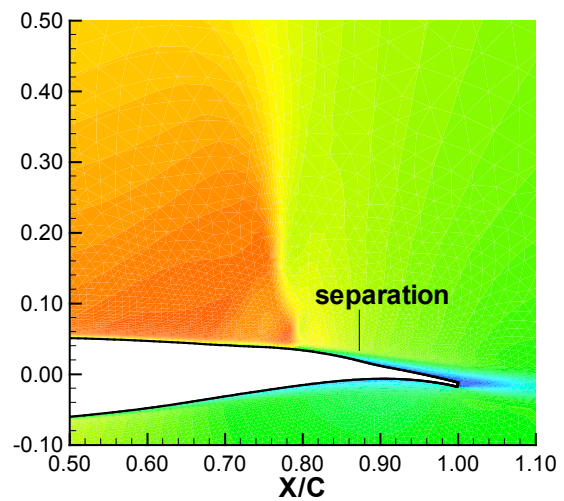

b)Bump $1, \Delta \mathrm{C}_{\mathrm{d}}=-12 \%$

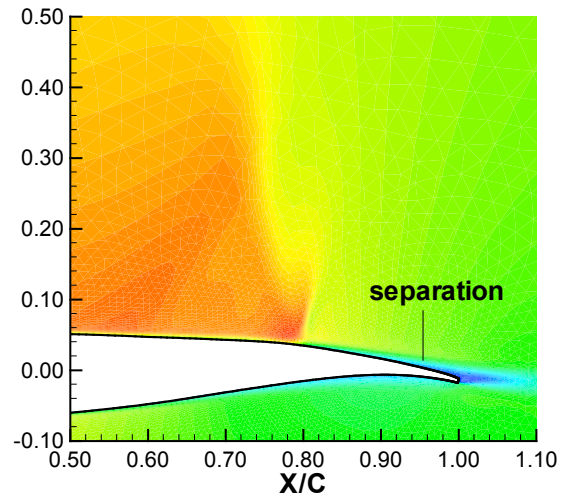

c)Bump3, $\Delta \mathrm{C}_{\mathrm{d}}=-15 \%$

Figure 9: Effect of contour bump on predicted Mach number contours for the NASA TMA-0712 airfoil $\left(M_{\infty}=0.78, C_{l}=0.70, \operatorname{Re}=30 \times 10^{6}\right)$. 
To further examine the effect of the contour bumps on the flow field, predicted Mach number contours in the vicinity of the shock wave are shown in Fig. 9, for the design lift coefficient. On the baseline airfoil, a strong normal shock wave occurs at approximately $77 \%$ c, with the peak Mach number ahead of the shock wave approaching 1.30. The boundary layer is predicted to separate near the trailing edge at $95 \% \mathrm{c}$. With the application of the first contour bump, the shock wave is noticeably weaker, and a lambda-shaped shock wave pattern begins to develop. The peak Mach number ahead of the normal shock wave is reduced to approximately 1.20. However the boundary layer separation increases due to the added curvature of the contour bump, and a stronger downstream pressure recovery. With the third contour bump configuration, the normal shock wave location is nearly identical to that of the first bump, but the lambda shock wave extends further upstream. The peak Mach number ahead of the shock wave for this case is slightly higher at 1.25 , but the boundary layer separation has moved downstream to $95 \%$ c. This is attributed to a more gradual re-compression near the trailing edge, as compared to the first contour bump. The surface pressure distributions will be discussed in detail below.

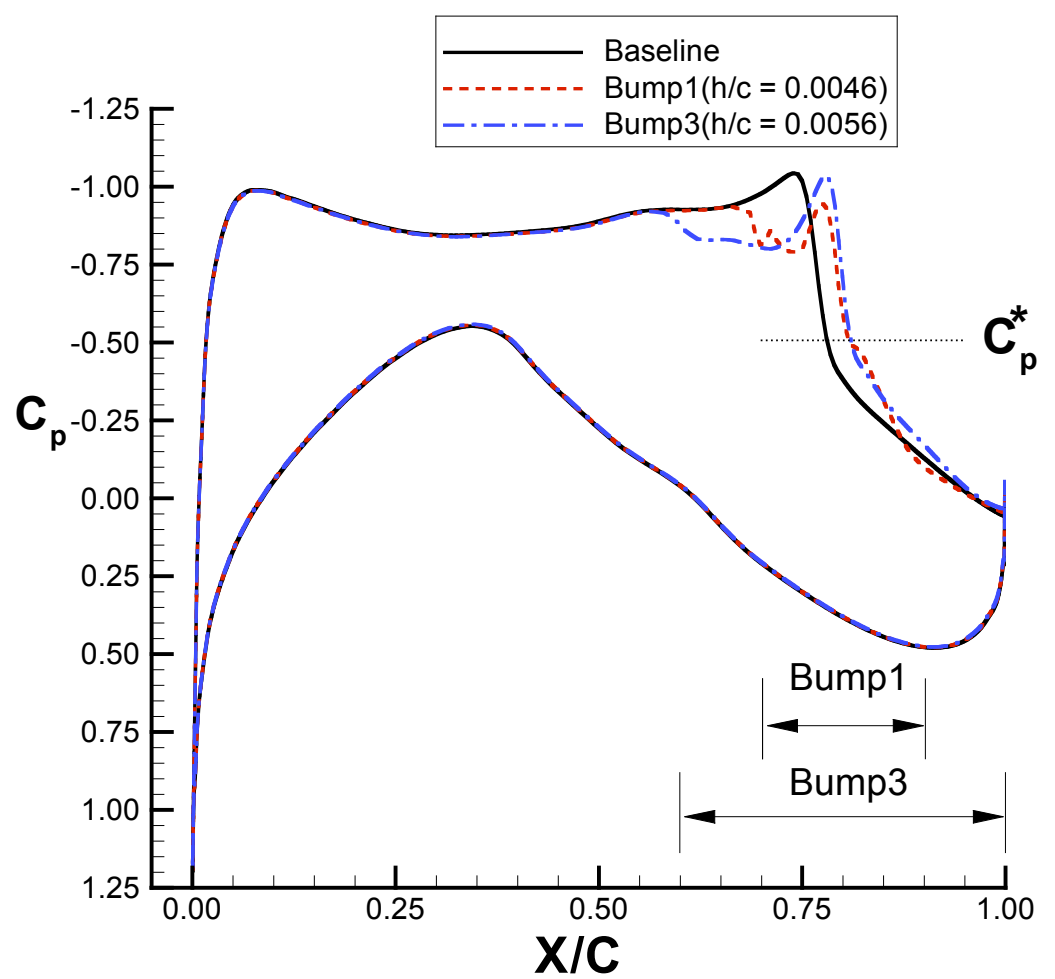

Figure 10: Effect of contour bump on predicted surface pressure distribution of the NASA TMA-0712 airfoil $\left(M_{\infty}=0.78, C_{1}=0.70, R e=30 \times 10^{6}\right)$.

Figure 10 presents the effect of the contour bumps on the surface pressure distributions for the same flow conditions discussed above. Both bumps shift the normal shock wave downstream by approximately $2.5 \% \mathrm{c}$. The upstream influence of each bump is isolated to a small region upstream of their respective starting positions, due to the upstream communication through the subsonic portion of the boundary layer. The oblique shock waves created at the beginning of each bump produce similar levels of compression. The first bump does produce the weakest normal shock wave, however the boundary layer separation occurring at $90 \% \mathrm{c}$, accounts for the higher drag as compared to Bump3. The Bump3 geometry produces a more gradual recompression downstream of the normal shock wave, allowing the boundary layer to remain attached longer. One can also appreciate the increase in the nose down pitching moment with this comparison, which was discussed previously.

The final comparison of this section focuses on the drag divergence properties of the initial bump configurations, shown in Fig. 11, for the design lift coefficient. At Mach numbers below 0.77, the current fixed contour bump shapes create a significant drag penalty, due to stronger shock wave strength as compared to the baseline airfoil. Above this Mach number, the fixed contour bumps are quite beneficial. This further indicates that an active contour bump, which could be deployed when needed, would be required for application on a wing. This figure also demonstrates that the current contour bumps can increase the drag divergence Mach number by 0.005 above the baseline airfoil value, increasing it to 0.78 . 


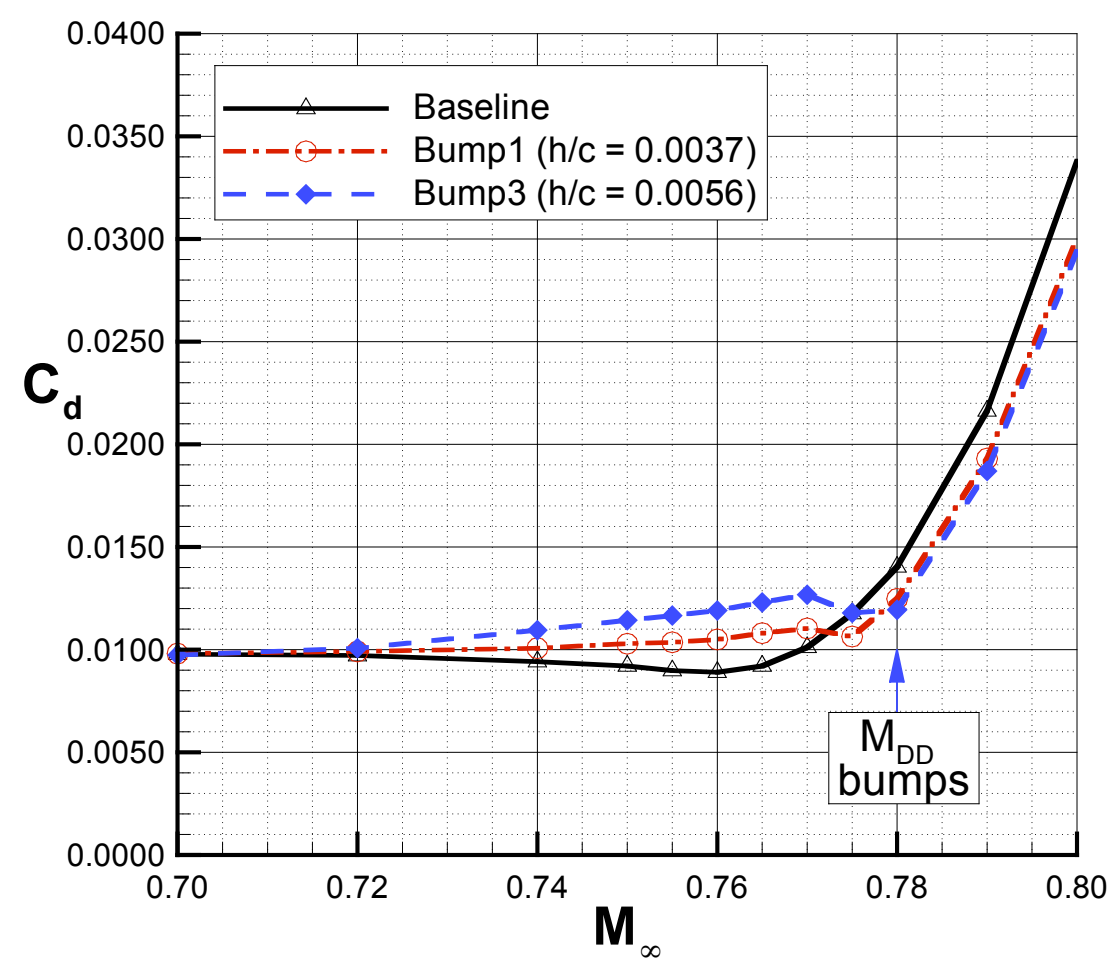

Figure 11: Effect of contour bumps on the drag divergence characteristics of the NASA TMA-0712 airfoil $\left(C_{1}=0.70, \operatorname{Re}=30 \times 10^{6}\right)$.

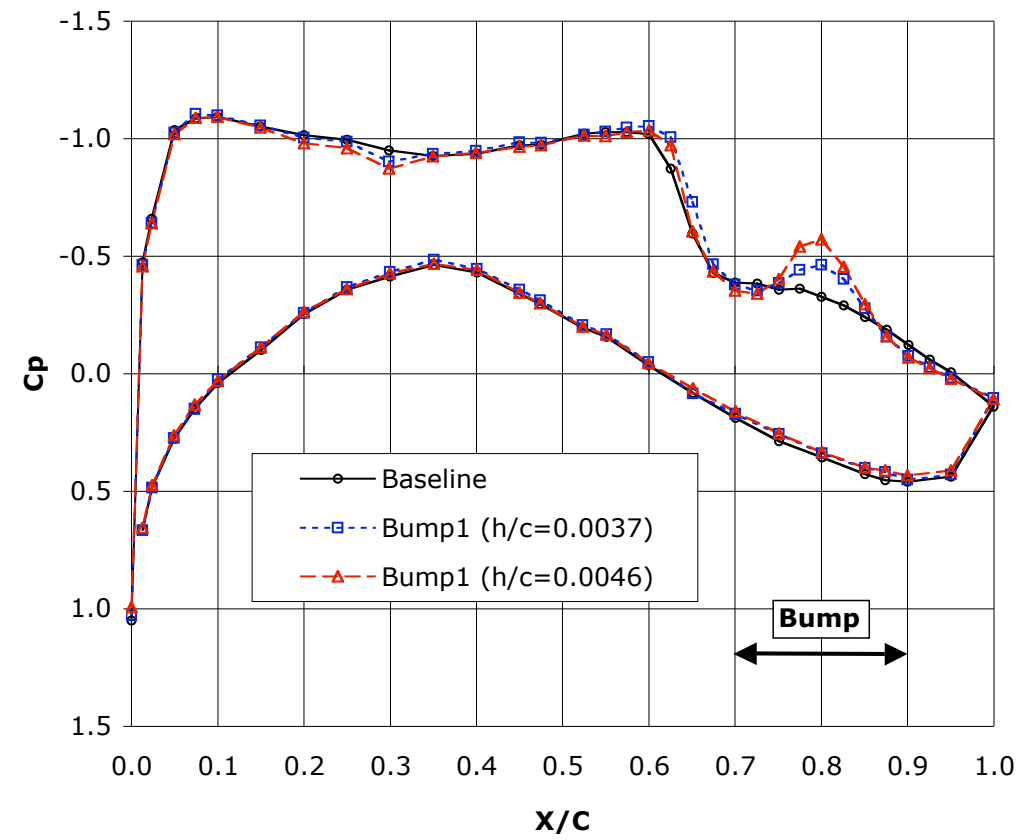

Figure 12: Shocks and original contour bumps are not in the same location for the NASA TMA-0712 airfoil tested in $0.3 \mathrm{~m}$ TCT experiment $\left(\mathrm{C}_{\mathrm{l}}=\mathbf{0 . 7 0}, \mathrm{M}_{\infty}=0.78, \mathrm{Re}=30 \times 10^{6}\right)$.

\section{B. Preliminary Experimental Data}

The wind tunnel experiment began with extensive testing of the new baseline airfoil design to verify the performance characteristics and compare them to the computational results. After a number of comparisons of chord-wise pressure distributions at the off-design condition, it became clear that the shock wave location in the 
experiment was occurring upstream of the predicted one (see Fig. 10). In fact, two of the Bump1 heights were tested to see their effects on the shock location. The shock wave location did not significantly change for the three configurations tested as shown in Fig. 12. Attempts were made to determine why the shock wave location was different from the predicted one. The most probable cause for the difference was assumed to be the presence of the wind tunnel walls in the experiment, which were not modeled in the free-air computational results discussed above. The computational analysis was performed with free-air boundary conditions only, because the tunnel adaptive walls were to provide an approximation of similar boundary conditions. However, the implementation of the adaptive walls for this test provided results that make it appear as though some residual wall interference effects were present and may need to be compensated for in post-test data reductions.

The MSES flow solver was used to simulate the effects of the streamlined wall shapes on the flow over the airfoil. No significant results were obtained to explain the differences in shock location. In addition, different experimental techniques were used in an attempt to move the shock location rearward enough to interact with the contour bump. These attempts however failed, and finally the decision was made to design and locate a new contour bump at the experimentally observed shock location.

To design the new contour bump, MSES and CDISC were used to predict the new bump height and location. The input Mach number and lift coefficient were adjusted in MSES so that the predicted pressure distribution matched the shock wave location as closely as possible to that measured experimentally. The MSES/CDISC bump design predicted a drag reduction of approximately $8 \%$ for a bump with its crest located at $65 \% \mathrm{c}$ and a crest height of 0.020 -inch $(\mathrm{h} / \mathrm{c}=0.0033)$. This was not as large a drag reduction as originally planned, but it was measurable with the given experimental setup.

The Baseline airfoil configuration was modified to approximate the new temporary contour bump design. A photograph of the resulting contour bump is shown in Fig. 13. The bump was made using 0.020-inch diameter metal wire bonded to the airfoil surface at $65 \% \mathrm{c}$. This wire provided the fixed bump height at the desired location to interact with the shock wave. The wire was covered with a $0.001-0.002$ inch thick sheet of steel shim material that extended 0.5 -inches upstream and downstream of the metal wire to create a smooth contour bump surface. Thus the resulting contour bump had a length of $17 \%$ c. The leading and trailing edges of the contour bump were fared smoothly into the baseline airfoil shape. To continue to measure the chord-wise pressures in the same area as the

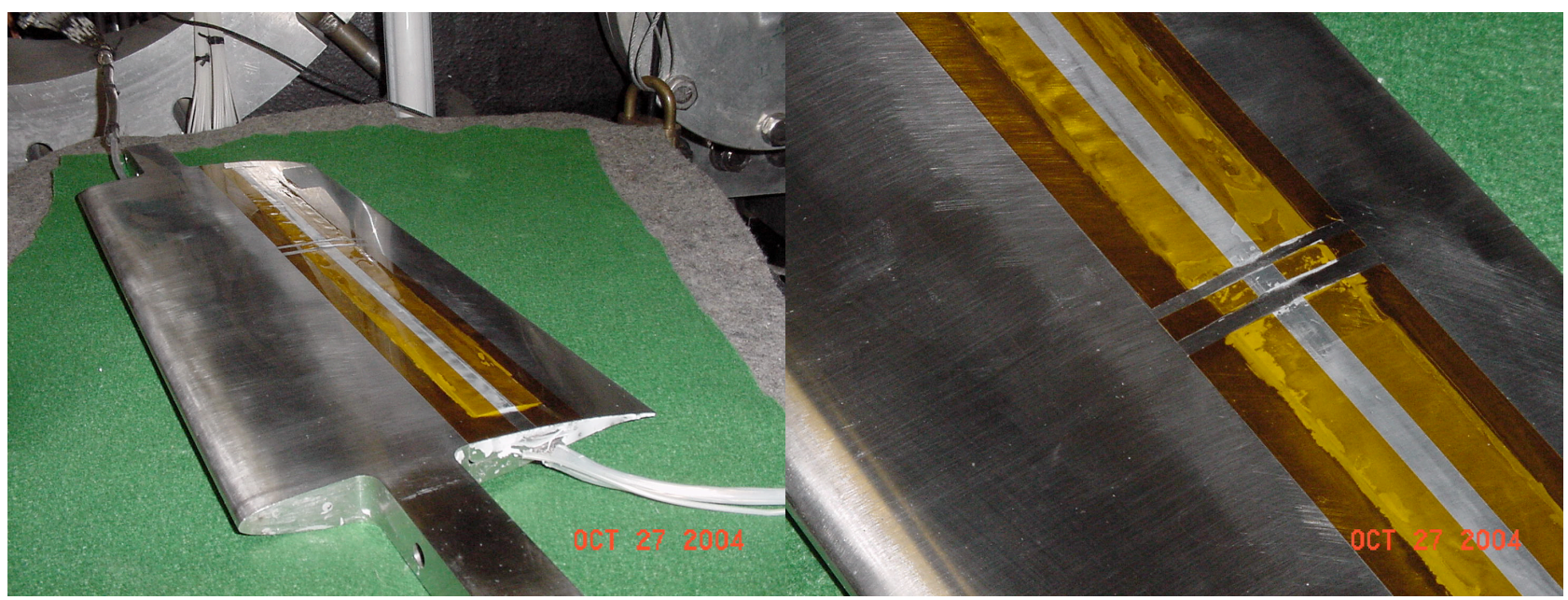

a) Sideview

b) Close up view at model centerline

Figure 13: Photograph of the Baseline airfoil model with a temporary contour bump $(\mathbf{h} / \mathbf{c}=\mathbf{0 . 0 0 3 3})$ placed with crest near the $\mathrm{x} / \mathrm{c}=\mathbf{0 . 6 5}$ location (measured shock location in the $0.3 \mathrm{~m}$ TCT experiment).

new contour bump, two gaps were made in the bump span so that the pressure orifices were not covered. It was assumed that the effects of the bump would carry over across the gaps. A photograph showing the close-up view of the gaps is presented in Fig. 13b.

Testing of the new contour bump provided data showing that bump effects were clearly present. The first effect was observed in the focusing Schlieren image data, Fig. 14. These data showed that the typically normal shock pattern observed repeatedly in the baseline configuration had changed to an oblique shock wave near the new 


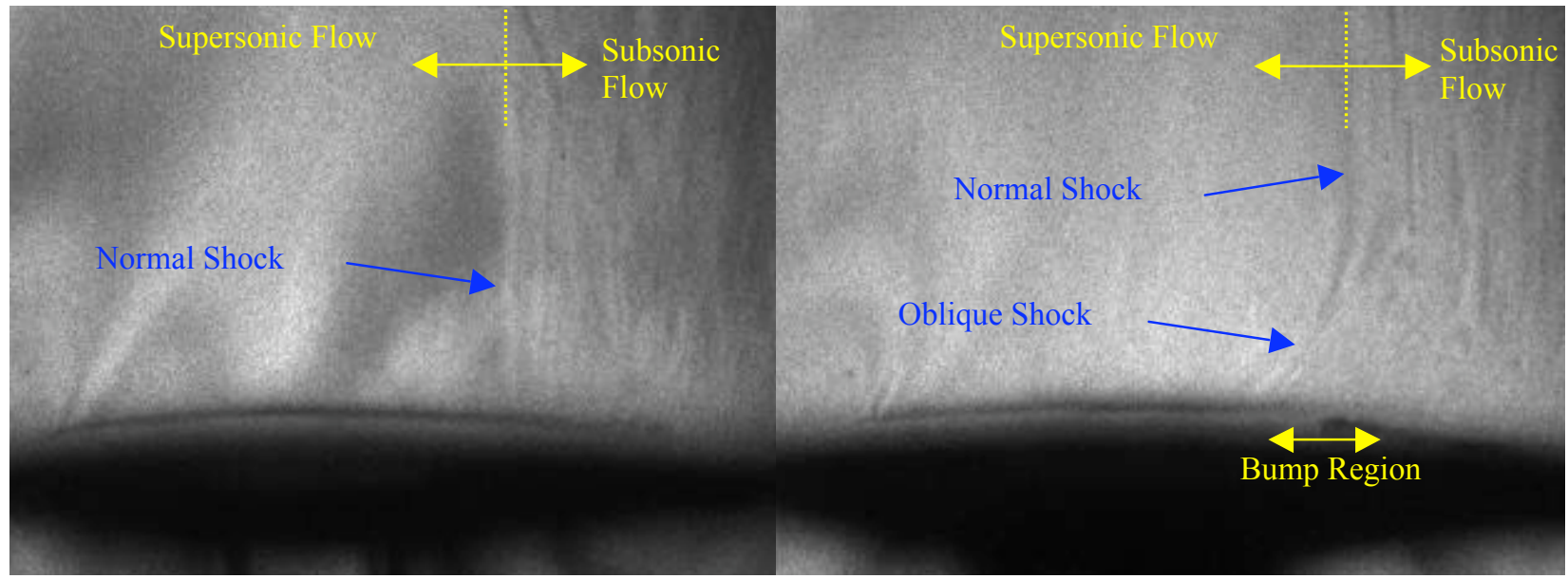

a) Baseline airfoil (no contour bump)

b) Baseline airfoil w/temporary contour bump

Figure 14: Focusing Schlieren images showing qualitatively the shock patterns observed in the $0.3 \mathrm{~m}$ TCT experiment $\left(C_{1}=0.7, M_{\infty}=0.78, R e=30 \times 10^{6}\right)$. Note that the tunnel flow direction is left to right.

contour bump. The bump-modified shock wave pattern clearly demonstrated the expected lambda-type shock wave pattern predicted in the computational analyses presented above as well as shown in previous research efforts (Refs. 5-10).

The second effect was observed in the chord-wise centerline pressure distribution data, exemplified by Fig. 15. The pressure distribution for the contour bump configuration produced a reduction in shock wave strength as compared to the baseline configuration. However, it should be noted that the contour bump configuration data had some significant differences in the upper surface leading-edge pressures, as well as the lower surface trailing-edge pressures. Based upon the CFD predictions shown in Fig. 10, these types of pressure distribution differences are not

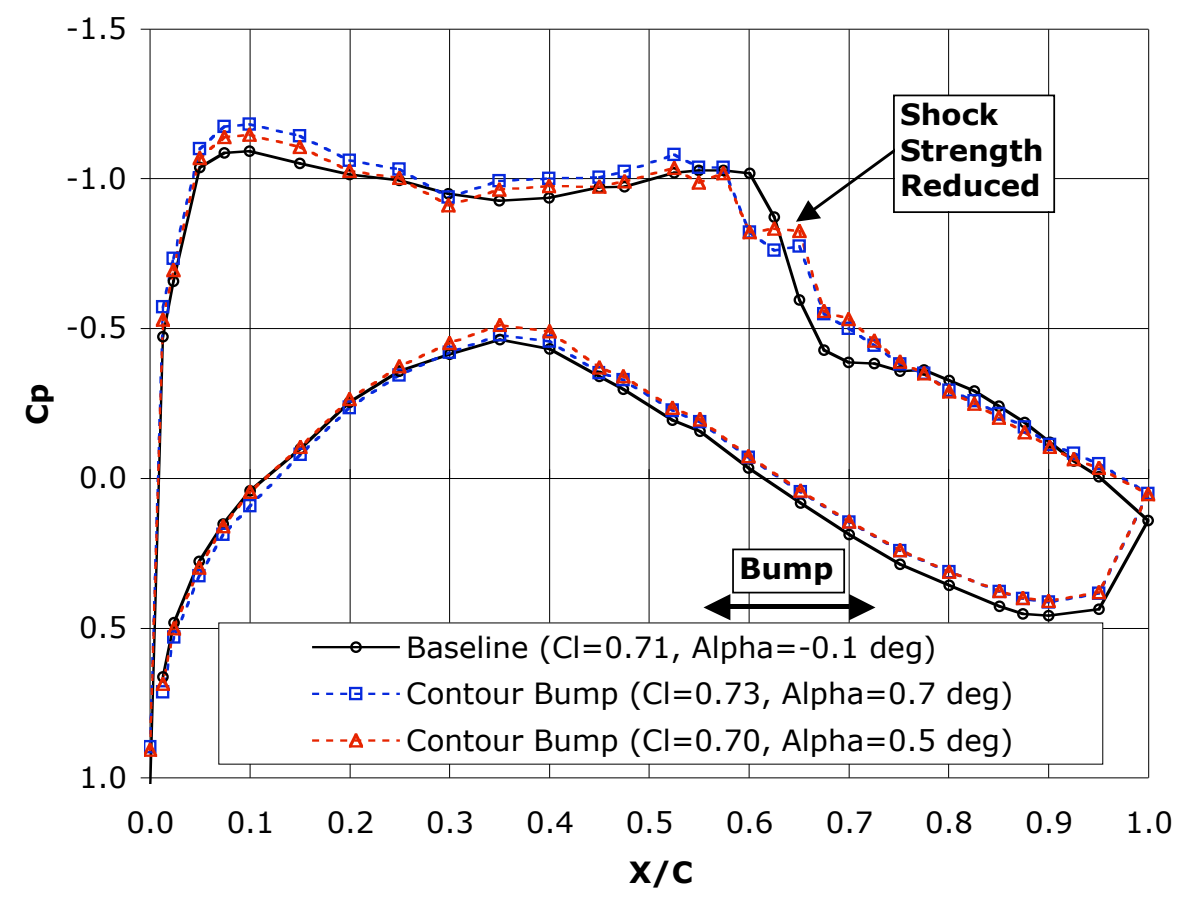

Figure 15: Comparison of chord-wise centerline pressure distributions to show effect of surface contour bump in the 0.3-m TCT experiment $\left(M_{\infty}=0.78, R e=30 \times 10^{6}\right)$. 
expected to be a result of the bump effect. Figure 12 also shows that experimentally the affected area is primarily near the bump region. Thus, the differences in the pressure distributions observed in Fig. 15 seem to suggest more than a localized bump effect.

The third contour bump effect was evident in the lift curves, shown in Fig. 16. Similar to the CFD predictions shown in Fig. 8, the contour bump decreases the lift at low angles-of-attack. At the higher lift coefficients, the lift increases as the shock wave moves aft along the airfoil to interact with the contour bump. The lift however, does not agree with the baseline values as expected in this regime. This difference could be explained by a shift in the angle-of-attack for the bump configuration, and may be an unresolved flow angularity. Even though the adaptive

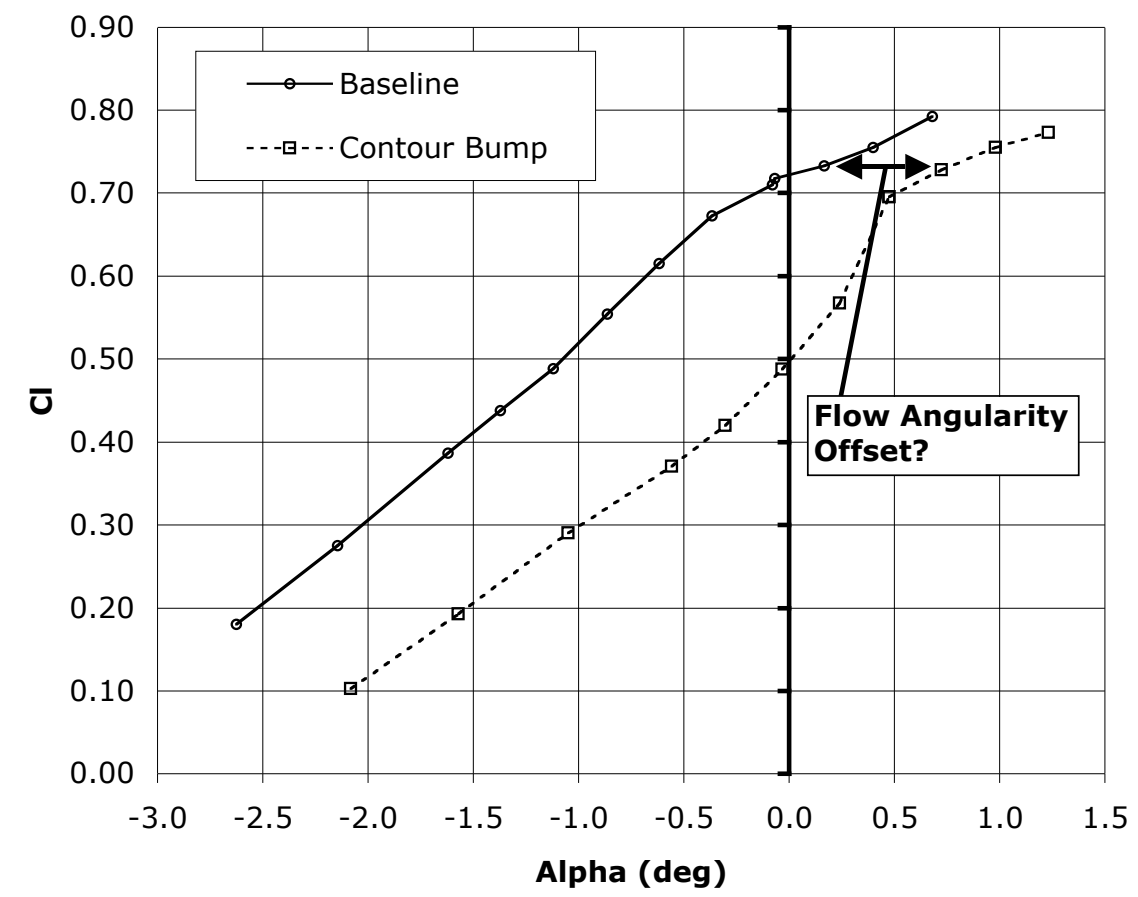

Figure 16: Comparison of the integrated lift results from the 0.3-m TCT experiment $\left(M_{\infty}=0.78, \operatorname{Re}=30 \times 10^{6}\right)$.

walls were streamlined to minimize wall interference for each angle-of-attack, these differences may also be attributed to residual wall interference effects, which still need to be addressed. The discussions below will reinforce this reality, but further insight into the effect of the new contour bump can still be deduced.

The fourth bump effect was observed in the wake rake survey data. These data show the loss of free-stream total energy due to the drag mechanisms associated with the airfoil. Figure 17 is presented to show a comparison of the wakes for both the baseline and the contour bump airfoil configurations. The effect associated with the contour bump wake profile is the valley that occurred between 0.0 to about 0.5 -inches above the tunnel centerline. The valley represents the reduced losses associated with the weaker oblique shock wave produced by the contour bump. Typically, this valley is not present in the wake behind a normal shock wave pattern. Instead a continuous ramp in the wake is observed similar to that seen for the baseline configuration between 0.0 and 1.0 -inch above the tunnel centerline. Even though the wake rake surveys showed the bump effect, the integrated drag values were higher than the baseline values. This is clearly shown in Fig. 18, where the drag polars are compared. A closer examination of each part of the wake surveys suggests that the two flow fields were indeed different. The normal shock wave region for the bump wake survey is stronger than that for the baseline configuration. Looking at the wake below the tunnel centerline reveals greater viscous drag losses for the bump wake profile than for the baseline. The bump should only produce localized effects, not global flow field changes as observed in these comparisons. 


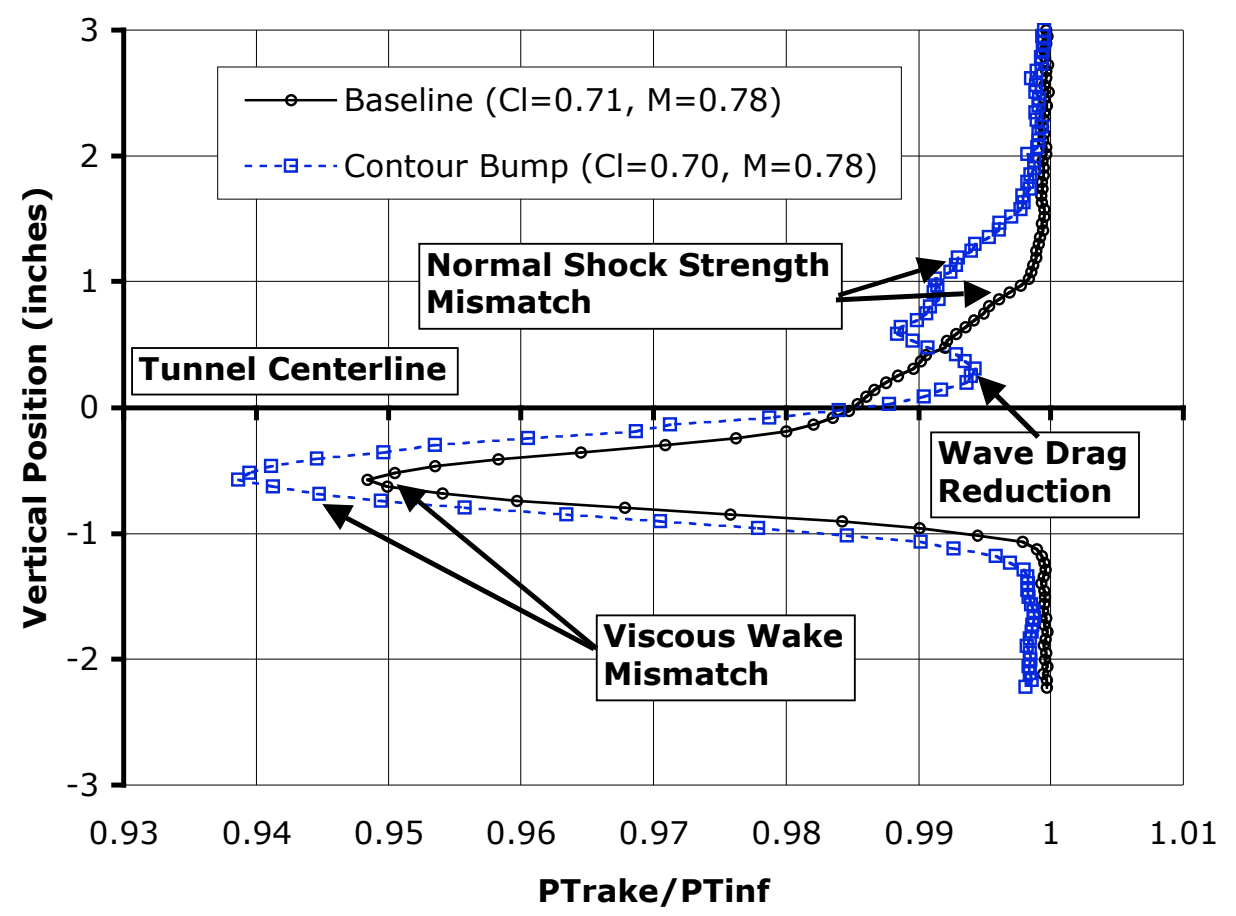

Figure 17: Comparison of Wake Rake Survey 3-chord lengths downstream of the model centerline in the 0.3-m TCT experiment $\left(M_{\infty}=0.78, \operatorname{Re}=30 \times 10^{6}\right)$.

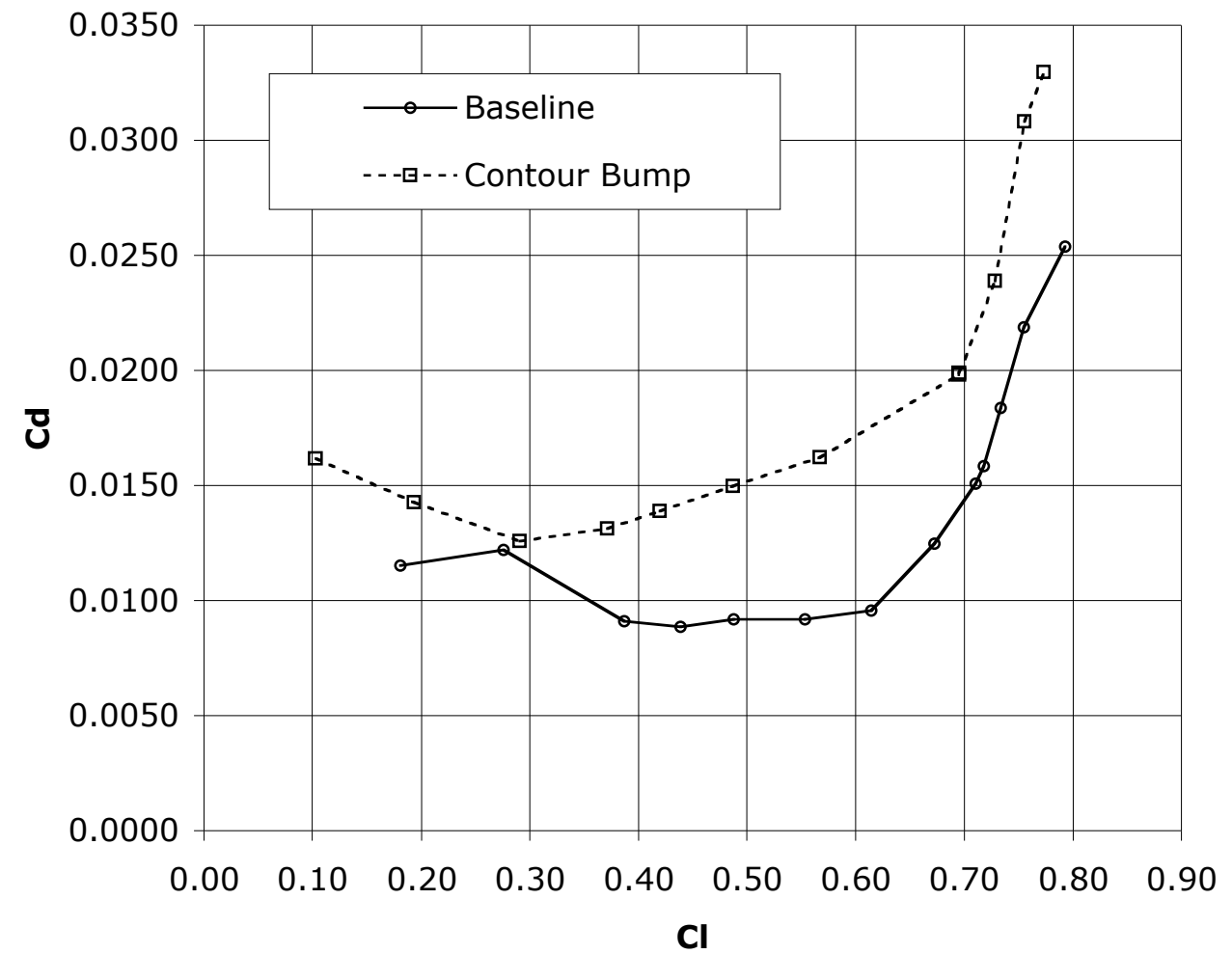

Figure 18: Comparison of the integrated drag polar results from the 0.3-m TCT experiment $\left(M_{\infty}=0.78, \operatorname{Re}=30 \times 10^{6}\right)$. 
To better understand why the bump effect on drag was not as expected, a comparison was made of different wake rake surveys to try and match the expected flow physics. The sensitivity of the wake rake surveys for the baseline configuration was examined to see if the flow physics in the wake could be matched. The effect of increasing the baseline configuration lift coefficient and Mach number are presented in Fig. 19a and 19b, respectively. In Fig. 19a, the increase in the lift coefficient matched the loss associated with the normal shock for both configurations at distances greater than 0.5 -inches above the tunnel centerline. However, the increased lift coefficient did not also produce a better match in the viscous wakes below the tunnel centerline. In Fig. 19b, the increase in the baseline configuration Mach number produced a better match in both the loss associated with the normal shock and the viscous wakes below the tunnel centerline. This finding suggested that there was indeed a difference in the Mach number for the two configuration flow fields.

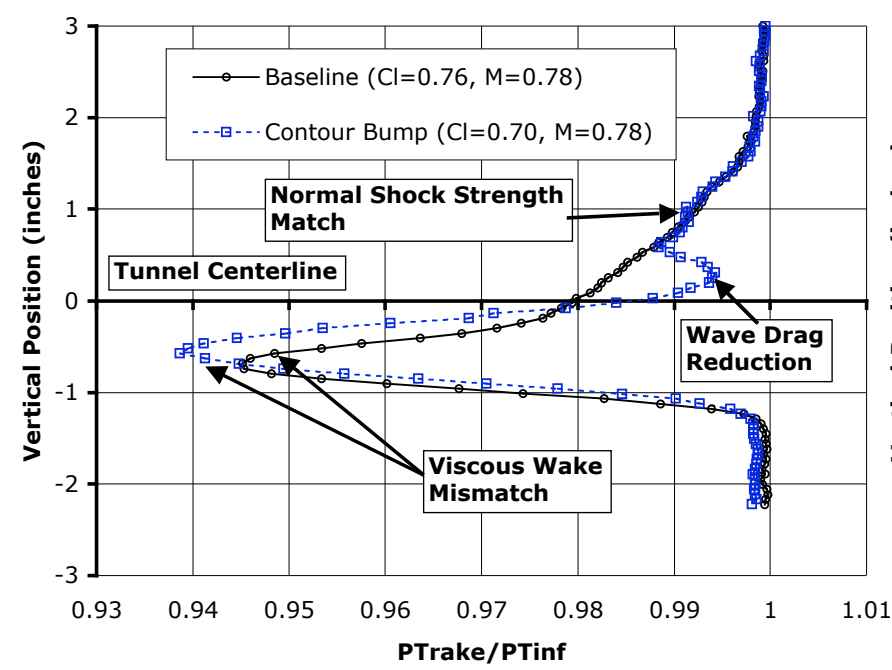

a) Increase Baseline $C_{l}$.

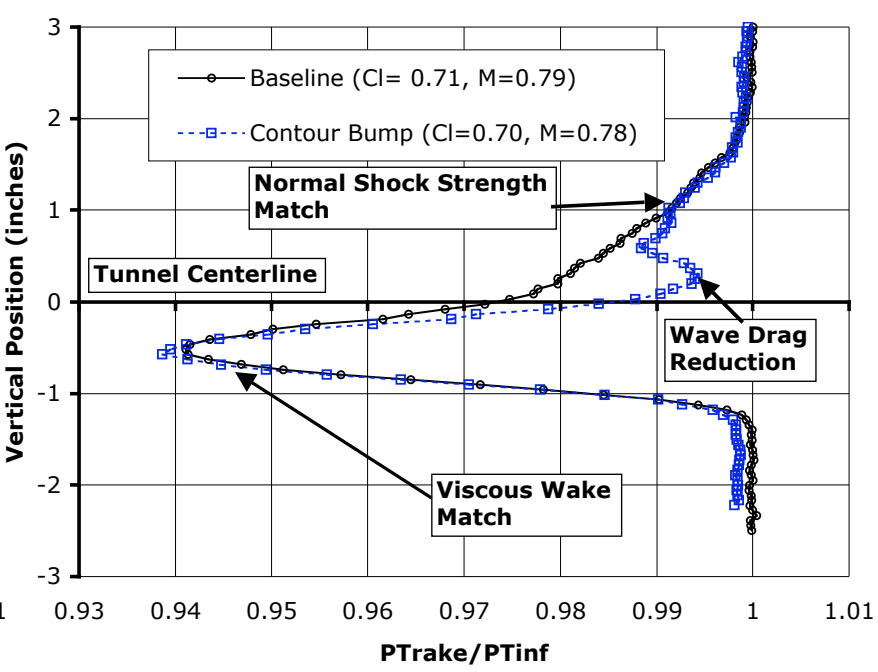

b) Increase Baseline $\mathbf{M}_{\infty}$.

Figure 19: Sensitivity of wake rake surveys to changes in $C_{1}$ and $M$ in the 0.3-m TCT experiment.

If the increased Mach number for the baseline configuration were used on the basis of matching the flow features in the wake profile, then the baseline configuration drag data at a Mach number of 0.79 would compare more directly to the contour bump configuration data at a Mach number of 0.78 . Note that the sensitivity for the baseline configuration to Mach changes was used because a more extensive data set for the baseline configuration existed than for the contour bump configuration. The resulting drag comparison is shown in Fig. 20. The contour bump configuration drag is lower than the baseline configuration (at Mach $=0.79$ ) for lift coefficients greater than about 0.68 . This modified drag comparison produced the expected contour bump drag reduction effect. At the design lift coefficient of 0.70 , the contour bump drag reduction from the baseline configuration was about 0.0020 out of 0.0230 , which is approximately a $9.0 \%$ drag reduction. This compares quiet favorably to the free-air CFD prediction of an $8.0 \%$ drag reduction for this new contour bump design.

The difference in Mach number between the baseline and contour bump configurations may make the reader wonder if the tunnel Mach number was somewhat questionable. The Mach number entering the test section was measured accurately in both cases. When the free stream Mach number is matched between two runs, then the Mach number coming into the test section entry plane is being matched. The problem shown above is due to the lack of maintaining that set Mach number along the test section through the adaptation of the tunnel walls to approximate streamlines in the flow field around the airfoil model. 


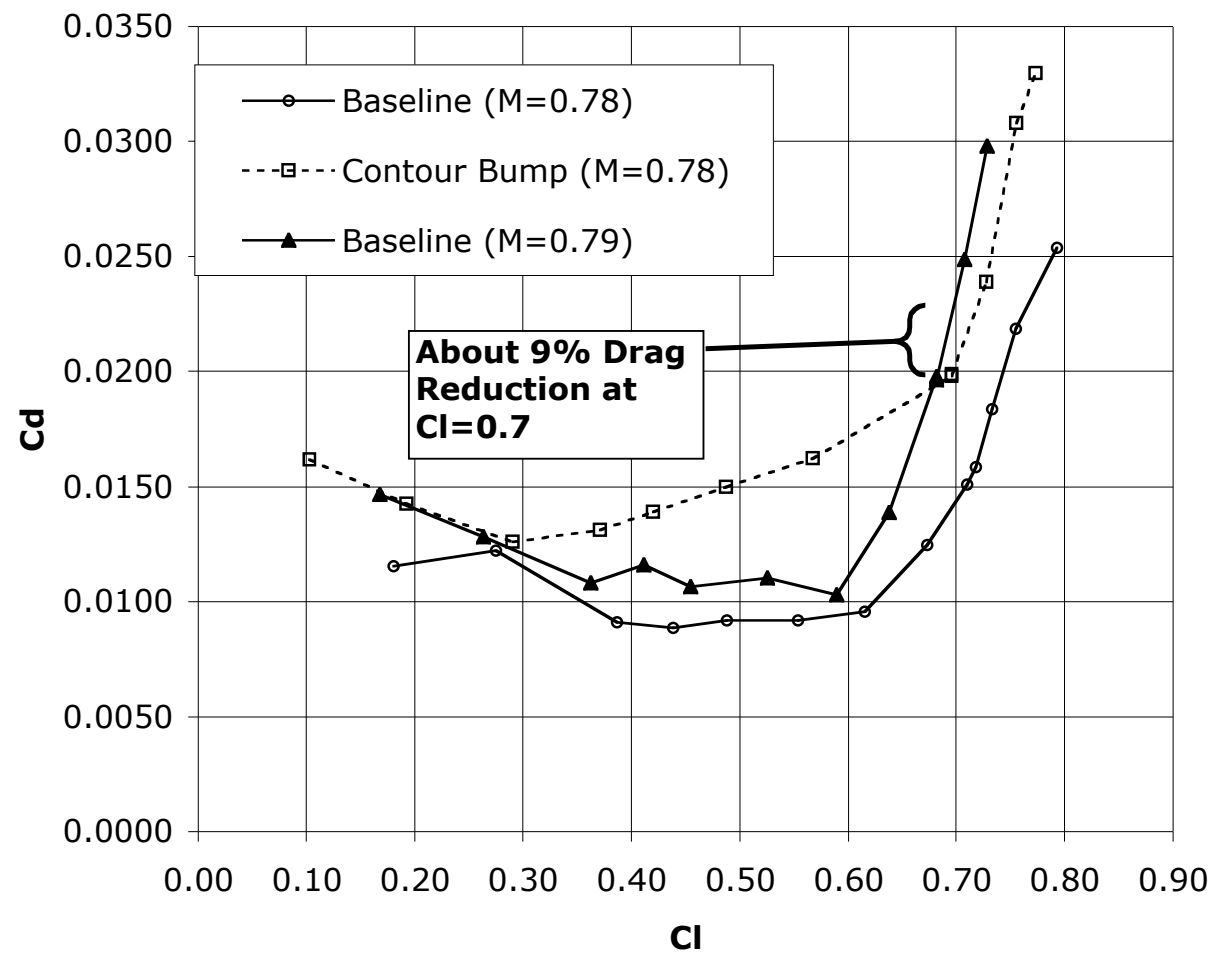

Figure 20: Comparison of the integrated drag polar results from the $0.3-\mathrm{m}$ TCT experiment $\left(\operatorname{Re}=30 \times 10^{6}\right)$.

Returning to the differences in the airfoil centerline pressure distributions noted earlier in Fig. 15, one might consider similar changes in the lift coefficient and Mach number to determine if the differences are reduced. In Fig. 21a, the increase in the baseline lift coefficient did provide a better match in the upper and lower surface leadingedge pressures. In Fig. 21b, the increase in the baseline Mach number did produce a somewhat better match in the lower surface pressures. To match the expected flow physics for the centerline pressure distributions, a combination of both a lift coefficient and a Mach number adjustment might be required, further underscoring the need for residual wall interference corrections.

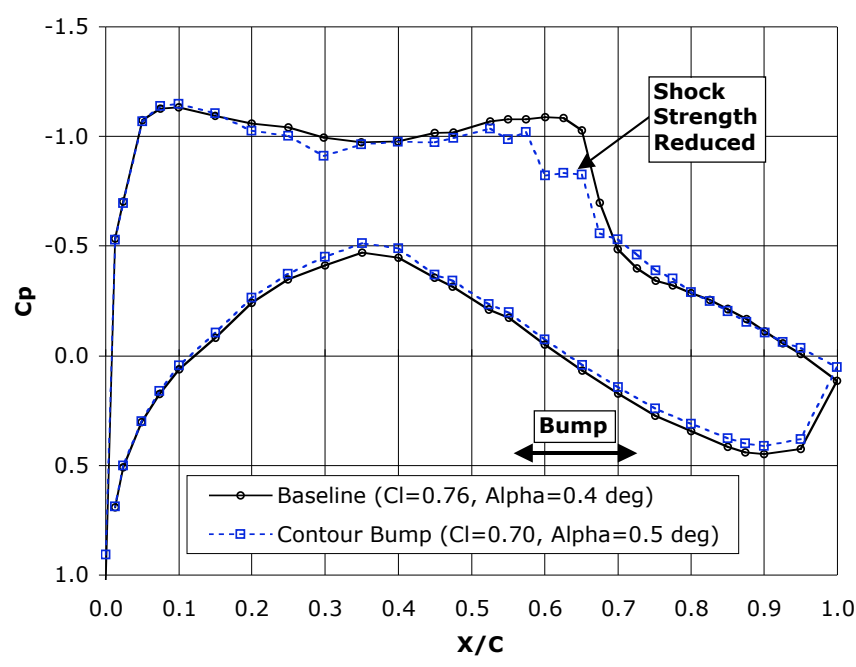

a) Increase Baseline $C_{l}$.

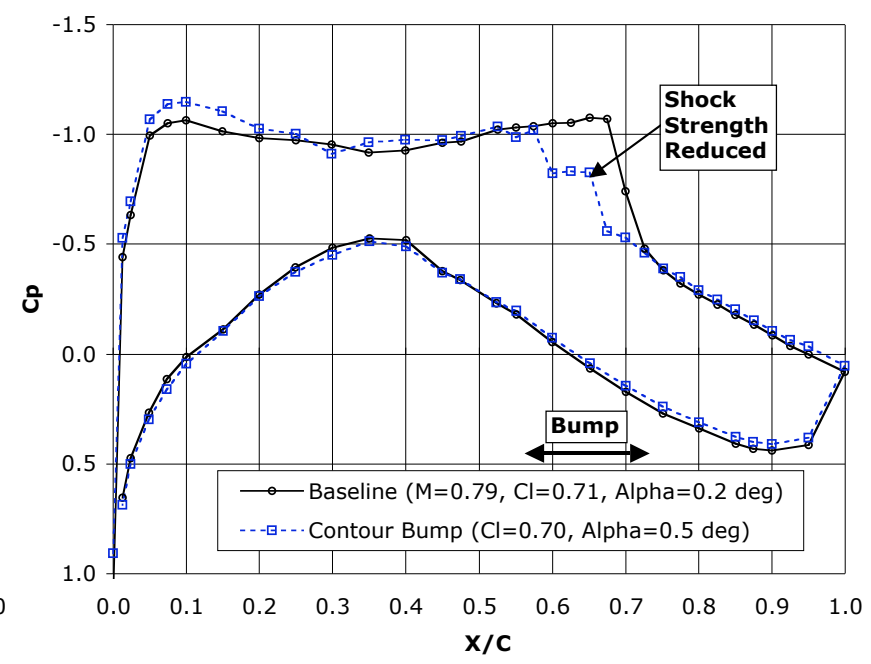

b) Increase Baseline $\mathbf{M}_{\infty}$.

Figure 21: Sensitivity of chord-wise centerline pressures to $C_{1}$ in the $0.3-\mathrm{m}$ TCT experiment $\left(M_{\infty}=0.78, \operatorname{Re}=30 \times 10^{6}\right)$. 
Finally, a comparison of the streamlined wall shapes for the baseline and contour bump cases discussed above are shown in Fig. 22. The wall shapes are plotted as a $\Delta z$ distribution, which is referenced to the non-deflected wall positions. The location of the airfoil model is noted. It is interesting to note that a top wall jack began to fail and was locked in place for the testing of the contour bump configuration. The wall shapes for the contour bump configuration stand out and look as though they are offset from the two baseline configuration conditions. The top wall jack at tunnel station 0.0 inches was the one that was locked in place and appeared to cause the wall shape offset. This difference suggests that the residual wall effects between the baseline and contour bump configurations may have been different enough to cause the observed flow physics mismatches discussed above. The magnitudes of the Mach number and lift coefficient changes used to match the flow physics were similar in size to those associated with residual wall interference effects observed in previous research in the 0.3-m TCT (Ref. 20). It is anticipated that once the residual wall interference corrections are applied to the current data set, the contour bump effects will be more clearly demonstrated. In addition, further CFD studies will be conducted to provide additional insight into the residual wall effects.

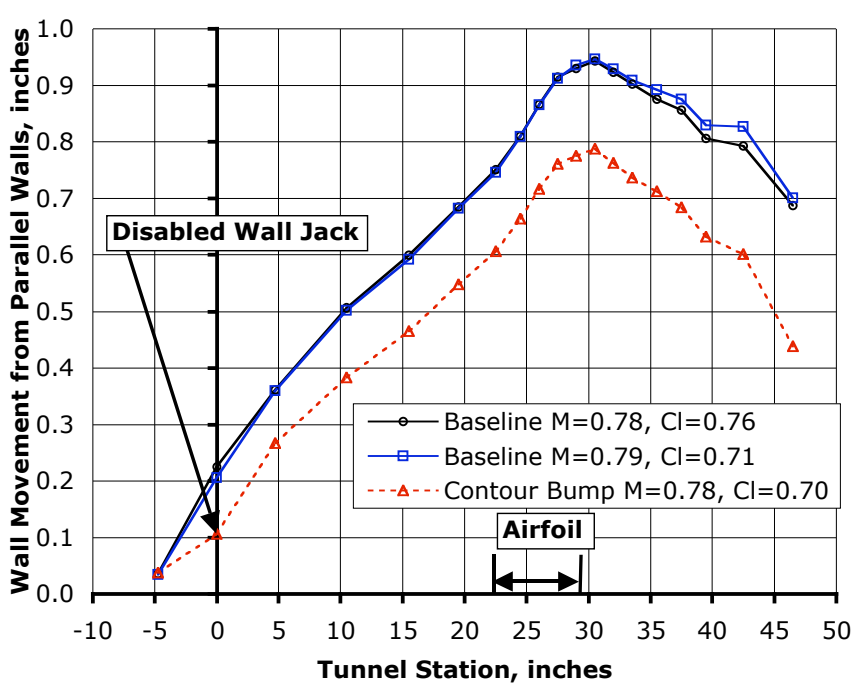

a) Top Wall Streamlined Shape.

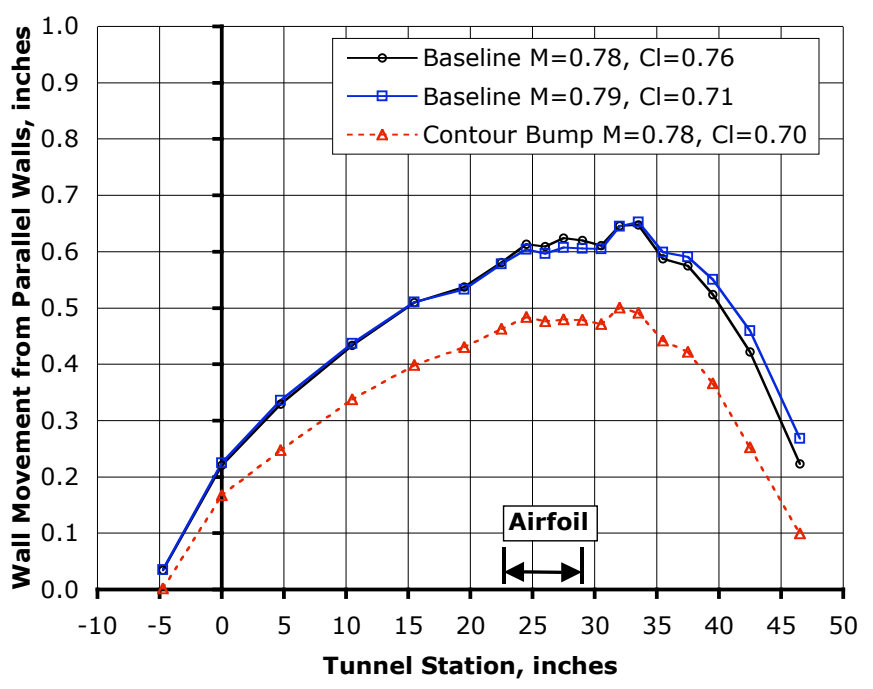

b) Bottom Wall Streamlined Shape.

Figure 22: Comparison of streamlined wall shapes from the 0.3-m TCT experiment $\left(\operatorname{Re}=30 \times 10^{6}\right)$.

\section{Conclusions}

The effect of discrete contour bumps on reducing the transonic drag at off-design conditions on an airfoil have been examined. The research focused on fully-turbulent flow conditions, at a realistic flight chord Reynolds number of 30 million. State-of-the-art computational fluid dynamics methods were used to design a new baseline airfoil, and a family of fixed contour bumps. The new configurations were experimentally evaluated in the $0.3-\mathrm{m}$ Transonic Cryogenic Tunnel at the Langley Research center, which utilizes an adaptive wall test section to minimize wall interference. The following conclusions can be drawn from the research:

1) The computational predictions indicated that the contour bumps generate significant drag reduction, in the range of $12.0 \%-15.0 \%$, at an off-design Mach number of 0.78 . The maximum height of the contour bumps was on the order of $0.005 \mathrm{c}$, with the crest of the contour bumps located $1.0 \%-2.0 \%$ chord downstream of the normal shock wave. The drag reduction occurred by modifying the strong normal shock wave on the baseline airfoil, by creating a weaker lambda-shaped shock wave pattern.

2) The computational results indicated that the fixed contour bumps performed well over a wide range of lift coefficients at the off-design Mach number of 0.78. At low lift coefficients, the contour bumps created a drag penalty due to the misalignment of the contour bump with the normal shock wave. The results demonstrated that an active contour bump, which could change height and move to follow the shock wave, would likely be required for application on an aircraft. 
3) The CFD results predicted that the current contour bumps increase the drag divergence Mach number of the baseline airfoil by 0.005 at the design lift coefficient of 0.70 . The results further underscored the benefits of an active contour bump system to avoid drag penalties at lower Mach numbers.

4) The experimentally measured normal shock wave location was found to be ahead of the predicted location for the off-design condition. The cause of this difference has not been fully understood, but is believed to be associated with residual wall interference effects. As a result, the performance of the manufactured contour bumps could not be evaluated. A modified contour bump was designed during the experiment and added to the baseline airfoil.

5) Preliminary analysis of the experimental results obtained for the modified contour bump demonstrated the predicted modification of the shock wave structure, with the contour bump clearly creating a weaker lambda-shaped shock wave pattern. However, the wake structures indicated that the residual wall interference for the modified contour bump configuration was more severe than that of the baseline configuration. Taking this into account, a revised analysis of the experimental data suggested that the modified contour bump reduced the drag by approximately $9.0 \%$ at the off design condition.

6) The preliminary analysis of the experimental data reinforced the need for applying residual wall interference corrections to the data. This is required to more clearly document to drag reduction potential of the modified contour bump. CFD studies will also be conducted to further assess the impact of the adaptive walls on the experimental data.

\section{Acknowledgements}

The authors would like to thank the many individuals whose contributions were key to making this research effort a success. Initially, the Aircraft Morphing project provided funding and technical support. The research was begun by Maria Pulsonetti who conducted through literature surveys and initial grid refinement studies. Currently the research is supported by the Efficient Aerodynamic Shapes and Integration project. During the design and analysis phases of this research, Dick Campbell, Mark Chaffin and Deepak Om provided invaluable technical discussions/consultations. This research also required the development and support of significant tunnel test systems that required the talents of many individuals. This group included Sundareswara Balakrishna and David Chan (adaptive walls system), Leonard Weinstein, Mike Talley, Bill Goad, Ed Massey and Linda Humber (focusing Schlieren system), Mike Chambers, Leon Harris, Frank Beltnick and John Zalarick (tunnel systems and hardware fabrication), David Sheldon, Craig "Beef” Hyle, Leon Adams, Steve Goodliffe, James Howard and Reginald Brown (electrical systems), Allen Kilgore and Pam Phillips (facility management/advocacy). The tireless efforts of the tunnel staff were key to conducting a thorough research test. These individuals made significant contributions daily throughout the research test. This group included Jerry Adcock, Stu Flechner, Stacy Sigmon, Tammy Price and Jeff Bullock. We also want to thank the individuals who made sure we obtained the highest quality of processed research data during the test. This group of individuals included Linda Mann, Mike Holter and Keith Forrest. Finally, the efforts of Salvatore Buccellato in managing the overall research efforts during our experiment, is greatly appreciated. All of these individuals made it possible for the authors to gain key insights in this research effort.

\section{References}

${ }^{1}$ Tai, T.C., "Theoretical Aspects of Dromedaryfoil," David W. Taylor Naval Ship Research and Development Center, Report 77-0104, November 1977.

${ }^{2}$ Tai, T.C.; Huson, G.G.; Hicks, R.M. and Gregorek, G.M., "Transonic Characteristics of a Humped Airfoil,” AIAA Paper 87-1239, June 1987.

${ }^{3}$ Stanewsky, E.; Delery, J.; Fulker, J. and Geißler, W., "Synopsis of the Project Euroshock," Notes on Numerical Fluid Mechanics, Vol. 56, 1997, pp. 1-81.

${ }^{4}$ Fulker, J.L., "The Euroshock Programme (A European Programe on Active and Passive Control of Shock Waves)," AIAA Paper 99-3174.

${ }^{5}$ Stanewsky, E.; Delery, J.; Fulker, J. and de Matteis, P., "Synopsis of the Project Euroshock II," Notes on Numerical Fluid Mechanics and Multidisciplinary Design, Vol. 80, 2002, pp. 1-124.

${ }^{6}$ Stanewsky, W., “Adaptive Wing and Flow Control Technology," Progress in Aerospace Sciences, Vol. 37, 2001, pp. 583-667.

${ }^{7}$ Sommerer, A.; Lutz, T. and Wagner, S., "Numerical Optimization of Adaptive Transonic Airfoils with Variable Camber," ICAS-2000-2.11.1. 
${ }^{8}$ Dargel, G. and Rodde, A.M., "Assessment of the Capability of Drag Reduction of the Shock Control Device 'SC Bump' on Airfoil Flows and Application Aspects on Wings," IUTAM Symposium on Mechanics of Passive and Active Flow Control, 1999, pp. 57-62

${ }^{9}$ Monner, H.P. and Th. Bein, H.H., "Design Aspects of the Adaptive Wing- The Elastic Trailing Edge and the Local Spoiler Bump," The Aeronautical Journal, February 2000, pp. 89-95.

${ }^{10}$ Bur, R.; Benay, B.; Corbel, B. And Delery, J., "Study of Control Devices Applied to a Transonic Shock Wave/Boundary Layer Interaction," Notes on Numerical Fluid Mechanics and Multidisciplinary Design, Vol. 80, 2002, pp. 133-152.

${ }^{11}$ McGowan, A. R., “AVST Morphing Project Research Summaries in Fiscal Year 2001,” NASA TM-2002-211769, August, 2002.

${ }^{12}$ Viken, S.A., "Comparison of a Navier-Stokes and a Coupled Euler/Integral Boundary Layer Flow Solver with Transonic Airfoil Experimental Results," M.S. Thesis, George Washington University, 1998.

${ }^{13}$ Campbell, R.L., "Efficient Viscous Design of Realistic Aircraft Configurations," AIAA Paper 98-2539, June 1998.

${ }^{14}$ Drela, M., "Design and Optimization Method for Multi-Element Airfoils," AIAA Paper 93-0969, Feb. 1993.

${ }^{15}$ Anderson, W.K. and Bonhaus, D.L., "An Implicit Upwind Algorithm for Computing Turbulent Flows on Unstructured Grids," Computers Fluids, Vol. 23, No. 1., 1994, pp. 1-21.

${ }^{16}$ Pabon, R., "Computational Study of Micro-vortex Generators with a Contour Bump for Drag Reduction on a Transonic Airfoil," M.S. Thesis, George Washington University, 2005.

${ }^{17}$ Marcum, D.L., "Generation of Unstructured Grids for Viscous Flow Applications." AIAA Paper 95-0212, Jan. 1995.

${ }^{18}$ Harris, C.D., "NASA Supercritical Airfoils: A Matrix of Family-Related Airfoils," NASA TP-2969, 1990.

${ }^{19}$ Mineck, R.E. and Hill, A.S., "Calibration of the 13-by 13-Inch Adaptive Wall Test Section for the Langley 0.3Meter Transonic Cryogenic Tunnel," NASA TP-3049, December 1990.

${ }^{20}$ Murthy, A.V., "A Study of Residual Interference Effects in Adaptive Wall Testing of a 7-Inch Chord CAST-102/DOA 2 Airfoil Model,” NASA CR-4390, August 1991. 